\title{
Receptor tyrosine kinases (RTKs) in breast cancer: signaling, therapeutic implications and challenges
}

\author{
Ramesh Butti ${ }^{1 \dagger}$, Sumit Das ${ }^{1 \dagger}$, Vinoth Prasanna Gunasekaran ${ }^{1 \dagger}$, Amit Singh Yadav ${ }^{1 \dagger}$, Dhiraj Kumar ${ }^{2}$
} and Gopal C. Kundu ${ }^{1 *}$

\begin{abstract}
Breast cancer is a multifactorial disease and driven by aberrant regulation of cell signaling pathways due to the acquisition of genetic and epigenetic changes. An array of growth factors and their receptors is involved in cancer development and metastasis. Receptor Tyrosine Kinases (RTKS) constitute a class of receptors that play important role in cancer progression. RTKs are cell surface receptors with specialized structural and biological features which respond to environmental cues by initiating appropriate signaling cascades in tumor cells. RTKs are known to regulate various downstream signaling pathways such as MAPK, PI3K/Akt and JAK/STAT. These pathways have a pivotal role in the regulation of cancer stemness, angiogenesis and metastasis. These pathways are also imperative for a reciprocal interaction of tumor and stromal cells. Multi-faceted role of RTKs renders them amenable to therapy in breast cancer. However, structural mutations, gene amplification and alternate pathway activation pose challenges to anti-RTK therapy.
\end{abstract}

Keywords: Brest cancer, Tumor microenvironment, Angiogenesis, Cancer Stem cells, Tumor-stroma interaction, Metastasis, Anti-RTK therapy, Drug resistance, Lapatinib, Trastuzumab, Bevacizumab, Alternate pathway activation

\section{Background}

Breast cancer is a major cause of morbidity and mortality among women population worldwide. The incidence of breast cancer differs considerably worldwide. It is expected to affect 0.2 million and would result in an estimated 41,070 deaths in 2017 in USA [1]. Breast cancer emerges as a consequence of dysregulation of different signaling pathways in mammary epithelial cells. Growth factors and chemokines activate various signaling cascades which cross-talk in tumor microenvironment leading to cancer progression. They bind to different families of receptors. Receptor Tyrosine Kinases (RTKs) comprise one such family. RTKs are single-pass transmembrane proteins, expressed on various cell types including the ones in the tumor

\footnotetext{
*Correspondence: kundu@nccs.res.in

${ }^{\dagger}$ Equal contributors

${ }^{1}$ Laboratory of Tumor Biology, Angiogenesis and Nanomedicine Research, National Centre for Cell Science, SP Pune University Campus, Pune 411007, India

Full list of author information is available at the end of the article
}

microenvironment. Overexpression of various types of RTKs such as epidermal growth factor receptors (EGFRs), vascular endothelial growth factor receptors (VEGFRs), platelet-derived growth factor receptors (PDGFRs), insulin-like growth factor receptors (IGFRs), and fibroblast growth factor receptors (FGFRs) is found in different types of cancer including breast [2-4]. Elevated levels of RTKs are associated with increased breast cancer aggressiveness and decreased overall and disease-free survival [5]. Ligand binding leads to conformational changes in RTKs that result in activation of downstream signaling molecules. The important pathways that are known to be activated by RTKs include mitogen-activated protein kinase (MAPK), Janus kinase (JAK)/ signal transducer and activator of transcription (STAT) and phosphoinositide 3kinase (PI3K)/Akt [6-10]. RTK-regulated pathways play key roles in various facets of cancer progression. RTKactivated signaling also induces cancer stem cell (CSC) phenotype that exhibit resistance to therapeutic regimens $[6,9]$. Cancer progression is not only regulated by autonomous signaling networks but also context-dependent 
molecular signals received from tumor stroma. Tumor stroma consists of various types of non-cancerous cells such as fibroblasts, endothelial cells, macrophages and other immune cells [11]. RTK signaling-regulated interplay between the tumor and stromal cells contributes to tissue remodeling, stromal cell recruitment and activation. Survival of disseminated cancer cells in metastatic sites requires formation of the pre-metastatic niche by stromal cells. Stromal cells expressing RTKs are known to be recruited to metastatic sites and have been found to form pre-metastatic niche through the RTK-regulated signaling [8]. RTKs also regulate trans-differentiation of cancer cells to endothelial cells to form new blood vessels in a process known as vasculogenic mimicry $[12,13]$. Since RTKs play important roles in different aspects of breast cancer progression, targeting RTKs might be useful in cancer treatment. Over the years, several RTK inhibitors have been screened and tested in clinical trials. Some of them such as lapatinib, trastuzumab and bevacizumab have been approved by Food and Drug Administration (FDA), USA for clinical management of breast cancer. Interestingly, RTK inhibitors revert conventional therapy-induced multidrug resistance and improve the disease-free survival in metastatic breast cancer patients [14]. Even though anti-RTK therapy shows clinical benefits in breast cancer patients, unfortunately, cancer cells develop de novo or acquired resistance that limits the success of RTK-targeted therapy [15]. In this review, we deal with EGFR, VEGFR, PDGFR and FGFR signaling in breast cancer progression, maintenance of cancer stem cell phenotype, tumor-stroma interaction and drug resistance. Moreover, this review also discusses the major challenges in targeting RTKs for the successful treatment of breast cancer.

\section{Structure and classification of RTKs}

Fifty eight different RTKs have been characterized in humans and they have been classified into 20 different subfamilies on the basis of structural features. Each RTK subfamily exhibits a prototype structural organization along with class-specific characteristics. A prototype RTK has an extracellular ligand-binding domain and intracellular tyrosine kinase domain separated by a transmembrane domain. The subfamilies of RTKs are (1) EGFR, (2) InsR, (3) PDGFR, (4) VEGFR, (5) FGFR, (6) PTK7/CCK4, (7) Trk, (8) Ror, (9) MuSK, (10) Met, (11) Axl, (12) Tie, (13) EphA/B, (14) Ret, (15) Ryk, (16) DDR1/2, (17) Ros, (18) LMR, (19) ALK and (20) SuRTK106/STYK1. The intracellular domain of RTKs has tyrosine kinase activity (tyrosine kinase domain; TKD). This tyrosine kinase domain can phosphorylate

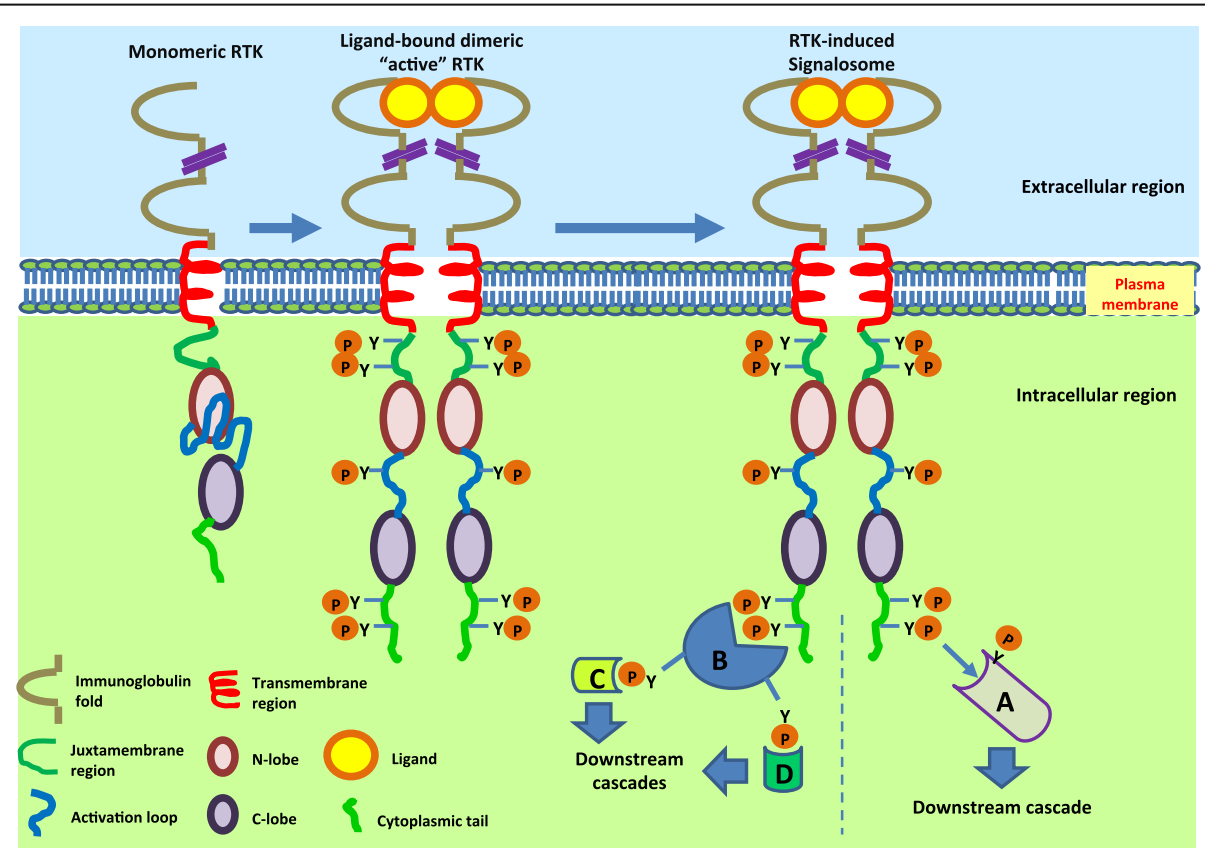

Fig. 1 Structure of prototype of receptor tyrosine kinase and mechanism of activation. Receptor tyrosine kinases (RTKs) have the following structural segments from N-to C-terminal: immunoglobulin folds, transmembrane region, juxtamembrane region, N-lobe, activation loop, C-lobe and cytoplasmic tail. RTKs reside at the plasma membrane as a monomer. Ligand binding crosslinks receptor molecules and induces conformational changes that lead to receptor autophosphorylation and activation. Phosphorylated RTK either serves as a docking site for adaptor proteins (B) or may directly phosphorylate signaling molecules (A). Adaptor proteins or signaling molecules bind to phosphorylated receptor through Src homology 2 ( $\mathrm{SH} 2)$ or phosphotyrosine-binding (PTB) domain. Docked adaptor proteins further transduce signal by phosphorylating other downstream molecules $(C, D)$ 
tyrosine residues in cis (within the same molecule) or in trans (residing on a different molecule) (Fig. 1). This consensus design of RTKs has been found to be conserved across evolution. Mutations in RTKs that result in structural abnormalities have been found to lead various disorders.

RTKs are activated by binding of soluble ligands. Some of the RTKs (DDR1, DDR2) are activated not by soluble ligands but by collagen fibers of the extracellular matrix [16]. Two compulsory events in RTK activation are ligand binding and receptor dimerization. Although the earlier idea was that cognate ligand binding ultimately results in the receptor dimerization, it has been found that few RTKs are oligomeric even in the absence of ligands [17]. EGFR is mostly present as a monomer whereas insulin receptor is present as a dimer on the cell membrane [18]. Nonetheless, receptor activation requires binding of ligand and consequent dimerization or oligomerization of the former in an active state. Different mechanisms for ligand binding-induced receptor dimerization have been explained for different classes of RTKs by different research groups. The mechanisms include two extremes where the dimer interface is formed entirely either by the ligand or the receptor molecules. The two other mechanisms include the participation of both ligand and receptor for the formation of the dimer interface and in another case participation of an accessory molecule. An example of the first mechanism is activation of nerve growth factor (NGF) receptor, TrkA where only two NGF molecules form the dimer interface and none of receptor extracellular domains make physical contact to the neighboring molecule [19, 20]. The ligands that activate members of the EGFR family do not themselves form dimers rather they bind two different domains of the same molecule and induce favorable conformational changes that lead to the formation of dimer interface by the receptor molecules [21]. Stem cell factor (SCF) binds to its receptor, KIT and induces receptor dimerization where the dimer interface is formed by both the ligand and receptor molecules [22]. In case of FGFR, heparin molecule stabilizes FGFR dimer configuration following ligand (fibroblast Growth factor (FGF)) binding [23].

In the absence of cognate ligands, the RTKs are held in an inactive state by autoinhibitory mechanisms. Two different autoinhibitory mechanisms have been described for different families of RTKs. The TKD of the RTKs contains three essential elements, $\mathrm{N}$ lobe, $\mathrm{C}$ lobe and activation loop [24]. In the activation loop-mediated autoinhibitory mechanism, the activation loop makes physical contact with the active site of TKD. A critical tyrosine residue in the activation loop is phosphorylated and the tyrosine kinase activity is autoinhibited in cis [25]. In the other mechanism, juxtamembrane sequences make extensive contact with the active site of the TKD and the latter is arrested in an autoinhibited inactive conformation [26-28]. Ligand binding induces favorable conformational changes that get rid of autoinhibitions following receptor dimerization. Activated RTKs can recruit many downstream effector molecules. These molecules contain $\mathrm{SH} 2$ or PTB domains which bind phosphotyrosine residues on RTKs [29]. These proteins can either interact directly with the activated RTKs or they may interact with other docking proteins which are tyrosine phosphorylated by RTKs. Some of the wellknown docking proteins which orchestrate the formation of large protein complexes downstream of RTK activation are FGF receptor substrate 2 (FRS2), insulin receptor substrate 1 (IRS1) and Grb2-associated binder 1 (Gab1). Some of the docking proteins have specificity in terms of which classes of RTKs they bind whereas other docking proteins bind RTK members across different families. A single RTK can bind different ligands. EGFR binds seven different ligands [30]. The strength of interaction with RTK varies for these different ligand molecules. The attributes of the active conformation of dimerized receptor differ greatly for different ligands. Different active dimer conformations of RTK activate different downstream signaling cascades [31]. Gene rearrangements and mutations confer certain structural features to RTKs that result in ligand-independent receptor dimerization and activation. Aberrant activation of RTKs by such means can lead to different pathophysiology. Gene rearrangements can lead to an abnormal coiled coil and leucine zipper conformations of the extracellular domain that induce ligand-independent association of RTKs. Mutations resulting in cysteine residues in the extracellular domain also can induce permanent association of two RTK monomers [32]. Transmembrane domain mutations also can result in constitutive dimerization of RTKs leading to certain pathophysiologies [33]. Apart from the classification outlined above, RTKs have also been categorized based on the commonality of downstream signaling and expression pattern across tissues. Three such classes are (1) EGFR/FGFR1/ c-Met, (2) IGF-1R/NTRK2 and (3) PDGFR $\beta$ [34].

\section{Breast cancer stem cells and drug resistance}

Despite the advent of new therapeutic avenues, tumor relapse remains to be a greater challenge in breast cancer management. There are various reasons for tumor recurrence including breast cancer stem-like cells (BCSCs) residing at primary tumor as well as at metastatic sites. CSCs are subpopulation of tumor cells which have the potential to self-renew and drive tumorigenesis. BCSCs are characterized by the expression of specific cell surface markers including $\mathrm{EpCAM}^{+} / \mathrm{CD} 24^{-} / \mathrm{CD} 44^{+}$ [35]. Moreover, it has been reported that CSCs also 
express high level of aldehyde dehydrogenase (ALDH) and it is associated with poor clinical outcome [36]. However, a recent study suggests that $\mathrm{EpCAM}^{+} / \mathrm{CD}_{24} /$ $\mathrm{CD}_{4} 4^{+} \mathrm{CSCs}$ are anatomically distinct from ALDH+ve CSCs. Molecular profiling of $\mathrm{EpCAM}^{+} / \mathrm{CD} 24^{-} / \mathrm{CD}_{4} 4^{+}$ and ALDH+ve CSCs revealed that the former subpopulations exhibit quiescent, epithelial to mesenchymal transition (EMT) phenotype whereas ALDH+ve CSCs show epithelial phenotype with self-renewal capacity [37]. Tumor microenvironment consists of cancerassociated fibroblasts (CAFs), tumor-associated macrophages (TAMs), mesenchymal stem cells (MSCs) and other immune and vascular cells and involved in the maintenance of CSCs in breast cancer [11, 38]. RTK signaling in tumor and stromal cells plays a critical role in the regulation of both $\mathrm{CD} 24^{-}$and $\mathrm{CD} 44^{+}$and $\mathrm{ALDH}+\mathrm{ve}$ CSC phenotypes. CSCs exhibit major impact on cancer therapy as they show resistance to conventional chemo therapies by expressing multi-drug resistance (MDR) genes. The $\mathrm{CD} 44^{+} / \mathrm{CD} 24^{-}$tumor cell fraction is increased in breast cancer patients upon administration of neoadjuvant chemotherapy [39]. Moreover, paclitaxel and epirubicin-based chemotherapy is associated with enrichment of ALDH+ve cells in breast tumors [40]. Altered expression/dysregulation of RTKs is associated with BCSC phenotype and drug resistance. Several reports suggest the treatment of breast cancer with RTK-based therapies reverses the multidrug resistance [41-43]. The role of RTK signaling in regulation of CSC phenotype and drug resistance has been discussed further.

\section{Role of receptor tyrosine kinase (RTK) signaling in breast cancer progression \\ EGFR: A key regulator of cancer stem cell phenotype and metastasis in inflammatory breast cancer}

EGFR is overexpressed in breast cancer tissues and is associated with higher aggressiveness and poor clinical outcomes [44, 45]. EGFR is a classic RTK and it undergoes homo or heterodimerization and transautophosphorylation upon ligand binding. EGFRs possess seven different cognate ligands including EGF, TGFo, betacellulin (BTC), heparin-binding EGF, amphiregulin (AREG), epiregulin, and epigen. The EGFR family consists of EGFR1 (EGFR, HER1, c-erbB1), HER2 (EGFR2, c-erbB2), EGFR3 (c-erbB3, HER3) and EGFR4 (c-erbB4, HER4) [46, 47]. Witton et al. have examined the expression of EGFR1, HER2, EGFR3 and EGFR4 using immunohistochemistry in 220 breast cancer patients and found overexpression of EGFR1 in 16.4\%, HER 2 in $22.8 \%$, EGFR3 in $17.5 \%$, and EGFR4 in $11.9 \%$ of breast cancer tissues. Increased expressions of EGFR1, HER2 or EGFR3 were associated with reduced survival whereas elevated level of EGFR4 was connected with better survival of breast cancer patients. It has been also reported that increased expressions of EGFR1, HER2 and EGFR3 were coupled with reduced expression of estrogen receptor (ER) [48]. Upon binding to the ligand, EGFR activates various downstream signaling molecules including Ras, PI3K, phospholipase C- $\gamma$ (PLC- $\gamma)$, and JAK leading to cell survival, cell growth, and tumor progression (Fig. 2) [6, 49, 50]. Various studies found that ER expression is inversely correlated with EGFR or cancer stem cell phenotype and that is well supported by the data that indicate higher expression of EGFR and presence of stem cell population in TNBCs which lack ER expression [51]. To investigate whether EGFR regulates stemness in breast cancer, Wise et al. have studied the enrichment of cancer stem cells under EGFR activation. They found that metalloproteinase-dependent activation of EGFR enriches $\mathrm{CD} 44^{+} / \mathrm{CD} 24^{-}$stem cells in TNBC through the MAPK/ERK pathway (Fig. 2) [6]. Inflammatory breast cancer (IBC) (especially inflammatory $\mathrm{TNBC}$ ) is a more lethal and aggressive form of breast cancer characterized by enrichment of chemo- and radio-resistant CSCs [52, 53]. Various reports suggest that EGFR signaling is important for IBC pathogenesis and progression $[54,55]$. Activation of NF- $\mathrm{kB}$ in IBC leads to ER downregulation and EGFR and/or ErbB2 overexpression and MAPK hyper-activation. MAPK signature distinguishes IBC from non-IBC tumors better than ER-based stratification (54). Wang et al. have identified that EGFR/cyclooxygenase-2 (COX-2) axisregulated nodal signaling promotes $\mathrm{CSC}$ phenotype and increases invasiveness of IBC cells through induction of EMT (Fig. 2) [55]. TGF- $\beta$-elicited EMT program augments expression of RTKs such as EGFR and IGF-1R which form cytoplasmic complexes with ER- $\alpha$ and Src leading to anti-estrogen resistance in breast cancer [56]. Syndecan-1 (CD138) is overexpressed and associated with cell proliferation and invasion, and emerged as an important drug target in IBC. Ibrahim et al. have established the relation between Syndecan-1 and EGFR in the regulation of cancer stem cell phenotype in inflammatory TNBC. Their studies revealed that Syndecan-1 regulates EGFR expression through activation of Notch signaling. Syndecan-1/Notch/EGFR crosstalk modulates interleukin-6 (IL-6), gp130 and other inflammatory cytokine expressions thereby promotes colony formation and stem cell marker expression through Akt-mediated NFKB activation (Fig. 2) [9].

Autophagy exhibits double-edged role in tumor progression depending on the context of a tumor. A recent study has revealed that autophagy regulates enrichment of ALDH+ve cancer stem-like cells via EGFR/Stat3 signaling in PyMT murine mammary cancer (Fig. 2) [57]. Tumor stroma also induces cancer stem cell phenotype by interacting with EGFR that is present on cancer cells 


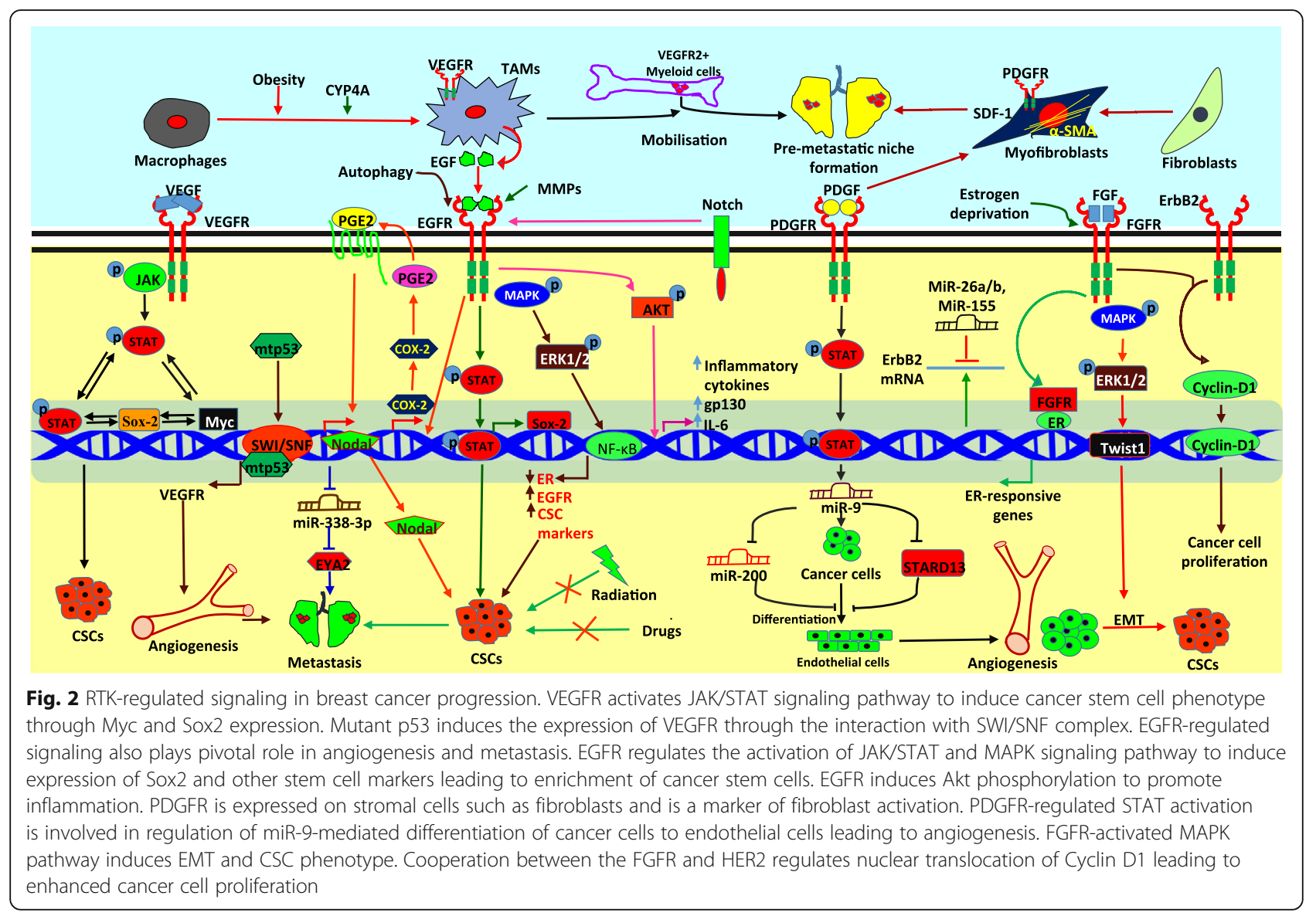

through different downstream molecular players [58]. In the similar line of evidence, Yang et al. have reported that activation of EGFRs in cancer cells by TAMs leads to the Stat3-mediated Sox2 expression that resulted in increased cancer stem cell population and metastasis in murine breast cancer models (Fig. 2) [59].

\section{VEGFRs: Master nodes in VEGF-regulated metastasis, tumor angiogenesis and lymphangiogenesis}

Various studies established that angiogenesis is indispensable for breast tumor progression. VEGFs are potent proangiogenic factors that bind to three different types of VEGFRs, VEGFR1 (Flt1), VEGFR2 (KDR or murine homolog, Flk1). VEGFRs are expressed on cancer, endothelial and other stromal cells. VEGFRs are typical RTKs contain an extracellular domain for ligand binding, a transmembrane domain, and a cytoplasmic domain which includes a tyrosine kinase domain (TKD) [38]. VEGF-A binds to both VEGFR1 and VEGFR2 to induce tumor angiogenesis whereas VEGF-C and D interact with VEGFR3 to promote lymphangiogenesis in different types of cancer $[38,60]$. However, Laakkonen et al. have reported that VEGF-C and VEGF-D-regulated VEGFR3 signaling induces tumor angiogenesis [61]. Chakraborty et al. have shown that osteopontin (OPN) augments VEGF-A expression in breast cancer cells and induces tumor growth and angiogenesis by regulating autocrine, paracrine and juxtacrine VEGF/VEGFR signaling in cancer and endothelial cells [62]. Srabovic et al. have reported that expression of VEGFR1 is significantly increased in breast tumor tissues as compared to benign tumors or healthy surrounding tissues, irrespective of the status of lymph node metastasis [63]. Kosaka et al. have identified elevated levels of VEGFR1 mRNA in peripheral blood of breast cancer patients and that is associated with cancer metastasis and recurrence and might be used for prognosis of breast cancer with basal-like and luminal type diseases [64]. In a recent study, Kapahi et al. have revealed that VEGFR1-710C/T polymorphism is associated with higher risk of breast cancer in North Indian population [65]. Ning et al. have revealed that VEGFR1 activation induces EMT of cancer cells thus promoting invasion and metastasis in breast cancer models [66]. Accumulated evidence suggests that infiltrated macrophages in tumor microenvironment promote malignant progression and enhance metastasis [11, 67]. A recent report has suggested that VEGFR1 signaling regulates obesity-induced tumorigenesis. Ablation of VEGF1 
in obese animals reduced breast cancer growth and lung metastasis by decreasing M2 macrophage polarization and affecting glucose metabolism (Fig. 2) [67]. A recent evidence suggests that Flt1+ve metastasis-associated macrophages (MAMs), a subset of TAMs are enriched in metastatic breast cancer as compared to primary tumors. Flt1 signaling in MAMs regulates a set of inflammatory genes imperative for cancer cell survival after metastatic seeding. In addition, circulating VEGFR1+ve myeloid cells are involved in pre-metastatic niche formation $[8,68]$. CYP4A polarized TAMs stimulate pre-metastatic niche formation and metastasis in lungs by mobilizing and recruiting VEGFR1+ve myeloid cells (Fig. 2) [68]. VEGR-2 is a key regulator of angiogenesis and overexpressed in breast cancer tissues [69]. Pfister et al. have studied the activation of VEGFR2 gene expression by mutant p53 in triple-negative breast cancer. In this study, they have shown that mutant p53 interacts with SWI/SNF and recruits to the promoter of VEGFR2 where this complex remodels the VEGFR2 promoter and induces the transcription leading to VEGFR-mediated breast tumor progression. These results indicate that mutant p53 gain of function is mediated by activation of VEGFR2 expression (Fig. 2) [70]. Collective evidences suggest that VEGFR2 exhibits prominent role in metastasis of breast cancer. However, the role of VEGFR2 in cancer cell invasion and migration is context-dependent. In breast tumor microenvironment, hypoxia induces $\mathrm{c}-\mathrm{Met} / \beta 1$ integrin complex formation that results in higher invasion and migration potential of cancer cells. However, VEGF-activated VEGFR2 binds directly with c-Met and $\beta 1$ integrin to prevent complex formation thus leading to sequestration of c-Met and $\beta 1$ integrin [71]. Zhao et al. have found that VEGF drives VEGFR2 expression and subsequently activates JAK2/STAT3 signaling-mediated Myc and Sox2 expression. VEGF/VEGFR2 axis-established autocrine loop consisting of STAT3, Myc and Sox2 which implicated in enhancement of cancer stem-like cell phenotype in TNBC (Fig. 2) [10]. Nonetheless, CSCs are responsible for cancer cell metastasis, drug resistance, and tumor relapse, perturbing VEGFR2/STAT3/Myc/Sox2 axis might be useful in overcoming the chemo-resistance in triple-negative breast cancer.

Lymphangiogenesis, formation of new lymphatic vessel plays a major role in cancer cell dissemination and distant metastasis. Hence, lymphangiogenesis is proved to be a promising target for the treatment of breast cancer. However, unavailability of specific markers for studying lymphatic vessels and lymphogenic metastasis delays the development of anti-lymphangiogenic therapy for management of different types of cancer [72]. VEGFR3 is a RTK expressed on lymphatic endothelial cells (LECs) and it plays a key role in lymphangiogenesis [20]. A recent study suggested that CCL21/CCR7 chemokine axis expressed on breast cancer cells interacts with VEGFR3 present on LECs to induce tumor-dependant lymphatic vascular recruitment and thereby lymphangiogenesis in breast cancer [73]. Lymphangiogenesis is also imperative for metastasis in postpartum breast cancer. Recent reports suggest that COX-2 induces VEGFR3 expression and lymphangiogenesis via VEGF-C/VEGFR3 axis to promote nodal metastasis of postpartum breast cancer $[74,75]$. VEGFR3 is indispensable for galectin-8mediated-crosstalk involving the VEGF-C, podoplanin and integrin pathways leading to lymphangiogenesis in breast cancer [76]. Based on above findings, targeting lymphangiogenesis using anti-VEGFR3 therapy might be useful in preventing tumor cell metastasis and increasing survival of breast cancer patients.

\section{PDGFR: promising role in tumor-stroma interaction in breast carcinoma}

PDGFRs are type III RTKs that are highly expressed in breast tumor and stromal cells. The PDGFR family consists of PDGFR- $\alpha$ and $\beta$ and both show similar kind of functions. PDGFR- $\alpha$ and $\beta$ are structurally similar and contain extracellular domain which consists of five immunoglobulin (Ig) - like folds and intracellular domains that exhibit kinase activity and consists of 100 amino acid residues dissimilar to other RTKs. PDGFs mostly bind to Ig-like domains 2 and 3, and induce homo or heterodimerization of the receptors. Moreover, these receptors are further stabilized by direct receptor-receptor interactions through Ig-like domain 4 after dimerization [77]. Aberrant activity of PDGFRs in different types of cancer including breast drives tumorigenesis. Various studies reported that PDGFR expression is associated with poor prognosis of breast cancer patients and it has prognostic and predictive potentials [78-80]. PDGFR is known to regulate various downstream signaling networks including Stat3 to support breast tumor initiation and progression [72]. Park et al. have reported that AF1q-induced STAT3 activation enhances breast cancer cell proliferation, angiogenesis and metastasis through PDGFR/Src signaling cascade [7]. Apart from directly regulating cancer cells, PDGFRs are also found to be expressed in reactive desmoplastic stroma that shows its possible role in tumor-stroma interaction. Bhardwaj et al. have found that PDGFR is expressed by $\alpha$-SMApositive myofibroblasts (cancer associated fibroblasts, CAFs) and endothelial cells in the periepithelial stroma of breast cancer tissues (Fig. 2) [79]. Paulsson et al. have examined the prognostic role of stromal PDGFR- $\beta$ expression using tissue microarrays (TMAs) of breast cancer. Their findings suggested that stromal PDGFR- $\beta$ exhibits most prominent prognostic significance in the subset of breast tumors. They also found that enhanced PDGFR expression is associated with reduced ER and 
PR and higher HER2 expression as well as inceased proliferation rate and tumor size [80]. In a similar line of evidence, Pinto et al. have shown that malignant stroma induces luminal breast cancer cell proliferation and angiogenesis in estrogen free-conditions through the PDGFR signaling cascade [81]. These results indicate the major role of PDGFR in breast cancer progression in absence of ER signaling. This notion is further supported by the fact that PDGFR induces endothelial differentiation of TNBC cells using in vitro tube formation and in vivo xenograft models. Moreover, D'Ippolito et al. have delineated the molecular mechanism by which PDGFRregulates endothelial differentiation of tumor cells in TNBC. PDGFR induced miR-9 expression promotes vasculogenic properties by targeting STARD13 and downregulating miR-200 in TNBC (Fig. 2) [13]. These results indicate that targeting PDGF/PDGFR in tumor microenvironment might be the promising therapeutic approaches for the treatment of TNBC.

\section{FGFR: aberrantly expressed in breast cancer and implications in targeted therapy}

The FGFR family members (FGFR1, FGFR2, FGFR3 and FGFR4) are comprised of an extracellular ligand-binding domain, a transmembrane domain and an intracellular tyrosine kinase (TK) domain. The extracellular domain has three Ig-like domains (IgI-III). The FGFs binding to FGFR leads to dimerization and subsequent activation of the intracellular kinase domain resulting in crossphosphorylation of tyrosine residues present on the cytoplasmic tail of the receptor [82]. Ras/MAPK and PI3K/Akt pathways are activated downstream to these receptors upon ligand stimulation. These pathways are known to be aberrantly activated in breast cancer and are involved in cell survival, proliferation, apoptosis and migration [83, 84]. The FGFRs harbour genetic aberrations such as amplifications of FGFR1, FGFR2 and FGFR4 and mutations in FGFR2 and FGFR4 genes in breast cancer [84-87]. Metastatic lobular breast carcinoma which shows poor response to chemotherapy demonstrates amplification of FGFR1 gene with implications in targeted therapy [86]. Formisano et al. have demonstrated that ER+ breast cancer shows amplification of FGFR1. They found that FGFR associates with ER $\alpha$ in nuclei of breast cancer cells and regulates ER-dependent genes in the presence of estrogen deprivation. In addition to ER+ breast cancer, amplification of FGFR1 gene correlated with poor prognosis in HER2- breast cancer [88]. Moreover, elevation of FGFR regulates tumor stroma remodelling and tumor recurrence in FGFR1-driven breast cancer [2]. Hence, studies with combinational therapies, targeting FGFR1 and other RTKs showed better results in cancer treatment as compared to targeting a single RTK. Single nucleotide polymorphisms (SNPs) in FGFR2 have been associated with an increased risk of $\mathrm{ER}+$ and $\mathrm{PR}+$ breast cancer [89]. Cerliani et al. have observed the interaction of FGFR2 with progesterone and STAT5 in breast tumor resulted in increased transcription of PR/STAT5-regulated genes [90]. Association of FGFR2 and FGFR3 expression with $\mathrm{ER}+$ breast cancer progression was observed [91]. Even though, role of FGFR3 in breast cancer progression has not been studied well, splice variants of FGFR3 are known to localize to nucleus of breast epithelial cancer cells [92]. Koziczak et al. have shown that FGFR4 and ErbB2 co-operately regulate cyclin D1 expression to promote cell proliferation in breast cancer [93]. FGFR signaling-regulated ERK1/2- mediated Twist1 positive feedback loop stabilizes a $\mathrm{CD} 44^{\text {high }}$ drug-resistant phenotype following ErbB inhibition (Fig. 2) [94]. Based on above findings, it is clear that FGFRs are mechanistically linked to the functions of other RTKs and drug resistance and may be a potential targets for treatment of breast cancer.

\section{Role of miRNAs and IncRNAs in regulation of RTK signaling}

In recent years, several studies have reported the role of microRNAs (miRNAs) and long non-coding RNAs (lncRNAs) in regulating the expression of components of different RTK signaling pathways. Tan et al. have shown that the level of ErbB2 in tamoxifen-resistant $\mathrm{ER}^{+}$ breast cancer is tightly regulated by interplay between miR-26a/b and human antigen $\mathrm{R}$ (HuR) (Fig. 2) [95]. miR-34a and miR-155 also regulate expression of ErbB2 at the post-transcriptional level (Fig. 2) [96, 97]. miR-24 targets two regulators (tyrosine-protein phosphatase non-receptor type 9 (PTPN9) and receptor type tyrosine protein phosphatase F (PTPRF)) of EGFR activation, thereby promoting metastasis of breast cancer [98]. EGFR is a direct target of miR-206 in breast cancer and the latter is induced in nuclear factor (erythroid-derived 2)-like 2 (NRF2)-deficient breast cancer [99]. In human breast cancer, H19 IncRNA-derived miR675 targets c$\mathrm{Cbl}$ and $\mathrm{Cbl}-\mathrm{b}, \mathrm{E} 3$ ubiquitin ligases which are known to degrade EGFR and c-MET thereby increases the stability of latter [100]. IncRNA CYTOR regulates the breast cancer progression through EGFR dependent pathway [101]. Another IncRNA, BCAR4 enhances the activity of ErbB2/3 receptors [102]. Role of different miRNAs and lnRNAs in the regulation of RTK signaling components are listed in Table 1.

\section{Role of RTK signaling in drug resistance}

Endocrine therapy is the treatment that specifically blocks the function of ER signaling using antagonists (tamoxifen, fulvestrant) or estrogen deprivation [103]. Almost $20 \%$ of the patients acquire resistance to ER- 
Table 1: Role of miRNAs and IncRNAs in the regulation of RTK signaling

\begin{tabular}{|c|c|c|c|c|}
\hline Serial No. & Molecule & miRNA/IncRNA & Target RTK pathway & Pathological function \\
\hline 1 & MiR-26a/b & miRNA & EGFR (ErbB2) & $\begin{array}{l}\text { Regulates expression of ErbB2; } \\
\text { competes with HuR for binding } \\
\text { to its } 3^{\prime} U T R \text { in tamoxifen-resistant } \\
\mathrm{ER}^{+} \text {breast cancer }[95]\end{array}$ \\
\hline 2 & MiR-34a & miRNA & EGFR (ErbB2) & $\begin{array}{l}\text { Downregulates expression of ErbB2 } \\
\text { [96] }\end{array}$ \\
\hline 3 & MiR-155 & miRNA & EGFR (ErbB2) & $\begin{array}{l}\text { Downregulates } \mathrm{HDAC2} \text {, a } \\
\text { transcriptional activator of ErbB2; } \\
\text { binds directly to a regulatory } \\
\text { sequence over the coding } \\
\text { region of ErbB2 [97] }\end{array}$ \\
\hline 4 & MiR-24 & miRNA & EGFR & $\begin{array}{l}\text { Regulates levels of phospho-EGFR } \\
\text { by targeting phosphatases, PTPN9 } \\
\text { and PTPRF [98] }\end{array}$ \\
\hline 5 & MiR206 & miRNA & EGFR, MET & Downregulates EGFR and c-MET [99] \\
\hline 6 & H19/miR675 & $\begin{array}{l}\text { IncRNA/daughter } \\
\text { miRNA }\end{array}$ & EGFR, MET & $\begin{array}{l}\text { Stabilizes EGFR and c-MET by } \\
\text { targeting c-Cbl and Cbl-b [100] }\end{array}$ \\
\hline 7 & CYTOR & IncRNA & EGFR & $\begin{array}{l}\text { Regulates expression of EGFR } \\
\text { pathway specific genes [101] }\end{array}$ \\
\hline 8 & BCAR4 & IncRNA & ErbB2/3 & $\begin{array}{l}\text { BCAR4 enhances ErbB2/3 activity in } \\
\text { tamoxifen-resistant breast cancer [102] }\end{array}$ \\
\hline
\end{tabular}

targeted therapy via activation of escape signaling pathways to overcome estrogen dependency [104]. Overexpression or activation of RTKs such as EGFR, HER2 and IGF1R leads to downregulation of ER and resistance to tamoxifen through activation of PI3K/Akt and MAPK pathways (Fig. 3) [105, 106]. EGFR/MAPK axis promotes phosphorylation of AF-1 domain of ER to enhance the ligand-independent activation of ER signaling [106, 107]. Activation of EGFR/ErbB2 signaling in tamoxifenresistant ER+ breast cancer cells induces highly

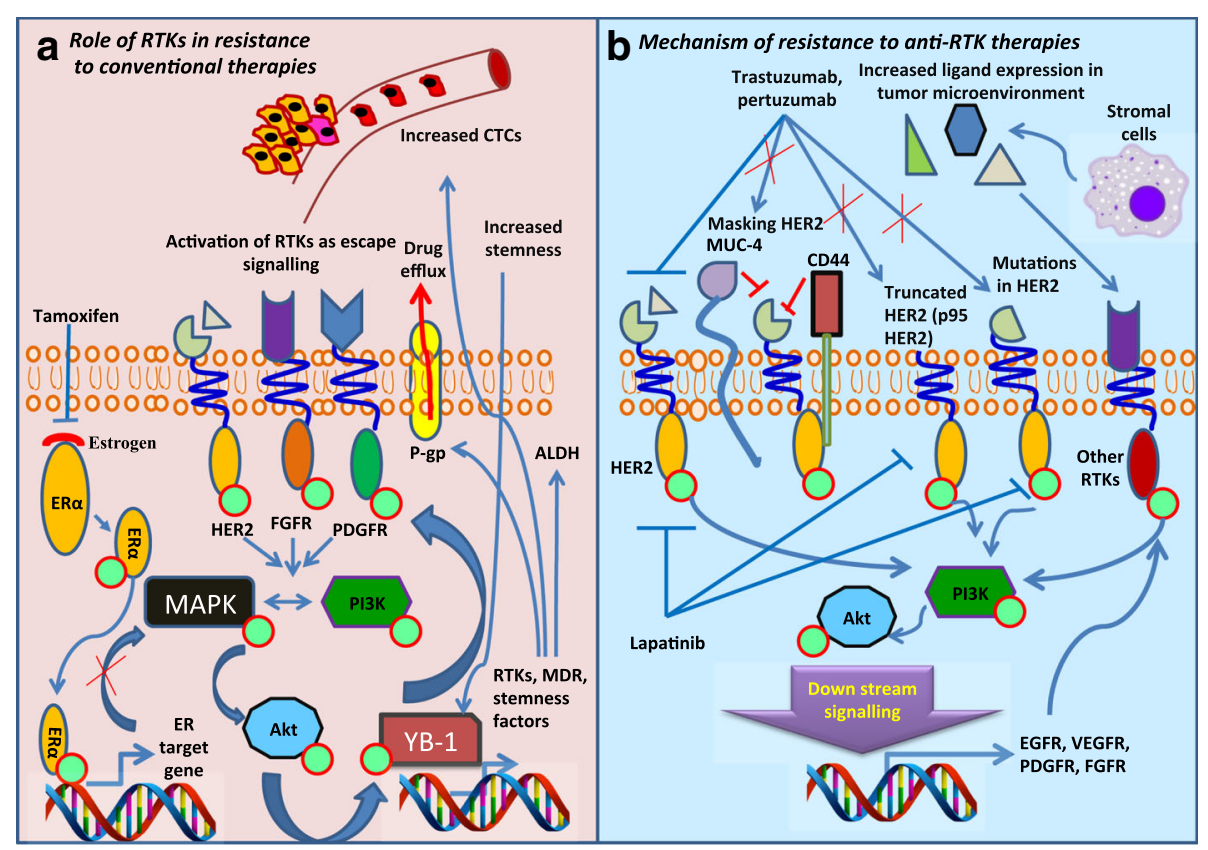

Fig. 3 RTK signaling in drug resistance. a Conventional chemotherapeutic agents reduce the cancer progression through the inhibition of MAPK PI3K/Akt signaling axis. Amplification and overexpression of RTKs including EGFR, HER2 and PDGFR reinforce the activation of PI3K/Akt/YB-1/RTK axis to maintain drug resistance; increases the kinase activity and thereby leading to cancer progression, drug efflux and cancer stemness. $\mathbf{b}$ Cancer cells exhibit resistance to RTK therapy due to disruption of interaction between drug and receptor or activation of alternate RTK signaling 
aggressive stem cell phenotype in these cells [108-110]. Inhibition of EGFR signaling using erlotinib considerably reduces the cancer stemness and reverses the endocrine resistance by inducing the expression of ER [111]. Moreover, HER2 amplification in ER-resistant breast cancer correlates with the ALDH+ stem cell population [108]. CSC population expresses a very high level of HER2 mRNA and protein as compared to the non-CSC population in endocrine-resistant patients. Higher activation of EGFR/HER2 might be the driving force in enriching CSC population in tamoxifen-resistant breast cancer [36, 108]. Association of HER2 expression with ER resistance has been explained in several reports. Whole exome sequencing studies revealed 13 mutations in different domains of HER2 in ER+ endocrine-resistant metastatic breast cancer patients [112]. These mutations produce different level of resistance to tamoxifen and fulvestrant in ER+ breast cancer cell lines. Moreover, ER cofactors, HOXB3 and HOXB7 are found to be overexpressed in tamoxifen-resistant breast cancer cells and enhance CSC phenotype. Myc-mediated transcriptional repression of miR-375 and miR-196a enhances the expression of HOXB3 and HOXB7 respectively [113, 114]. Retinoblastoma binding protein 2 (RBP2), an ER co-regulator is overexpressed in tamoxifen-resistant breast cancer patients and increases the stability of RTKs such as EGFR and HER2. Moreover, RBP2-ER-NRIP1-HDAC1 complex activates IGF1R through transcriptional repression of IGFBP4 and 5 [115]. Another ER transcriptional coactivator, mediator subunit 1 (MED1) is overexpressed in circulating tumor cells and primary breast tumor tissues following tamoxifen treatment leading to HER2mediated ER resistance. HER2-mediated phosphorylation of MED1 recruits the transcriptional corepressors such as HDAC1, N-CoR and SMART to the promoter of the ER-regulated genes in HER+ tamoxifen-resistant cells $[116,117]$.

Apart from the endocrine therapy, other types of treatment such as surgery, radiation therapy and cytotoxic drugs are also available for breast cancer. Mainly, anthracyclines (DNA damaging agents) and taxanes (microtubule-stabilizing agents) are widely used for breast cancer as adjuvant or neoadjuvant therapies [118]. However, the resistance to cytotoxic cancer drugs is the major drawback in cancer treatment. Multidrug resistance is mainly associated with cancer stemness and drug efflux driven by various survival signals [119]. Importantly, RTKs are key regulators of cancer stemness and associated with drug resistance in breast cancer cells. In general, various RTKs activate PI3K/Akt signaling to induce the expression of cancer stemness factors, multidrug resistance associated proteins and membrane transporters in cancer cells. Accumulating evidence clearly suggest that upregulation of RTKs including
EGFR, HER2, VEGFR and IGF-1R in course of chemotherapy is associated with overexpression/activation of drug efflux transporters [41, 42]. Jin et al. have shown the strong positive correlation between p-glycoprotein expression and EGFR with overall and disease-free survival [43]. Moreover, higher expressions of EGFR and HER2 are detected in doxorubicin-resistant MCF7 cells as compared to the doxorubicin-sensitive MCF7 cells. Overexpression of HER2 also induces resistance to various chemotherapeutic agents such as taxane, cyclophosphamide, methotrexate, epirubicin in breast cancer [120]. Moreover, HER2 expressing circulating tumor cells (CTCs) shows less sensitivity to the various chemotherapeutic agents including doxorubicin, docetaxel and 5-fluorouracil as compared to HER-negative CTCs [121]. Overexpression of RTKs is correlated with expression of transcription factors linked to drug resistance in breast cancer. YB-1 is a transcriptional/translational regulator and overexpressed in cancer stem cells. Nuclear localization of YB-1 is reported in cancer relapse and drug-resistant patients irrespective of ER and HER2 status. RTK-regulated PI3K/Akt phosphorylates YB-1 at Ser-102 to facilitate the nuclear localization. Furthermore, nuclear YB-1 binds to the specific promoter region and transcriptionally activates the expression of RTKs including EGFR, HER2 and VEGFR. Disturbance in YB-1/RTKs self-reinforcing loop significantly reduces the cancer stemness and drug efflux in breast cancer cells [122]. Moreover, YB-1 transcriptionally increases the expression of p-glycoproteins (MDR-1 and MDR-3) provokes the multidrug resistance in breast cancer (Fig. 3) $[123,124]$. TAMs are known to influence the maintenance of suitable microenvironment for cancer stem cells and sustained drug resistance in breast cancer. TAMs produce the higher level of cytokines, TGF $\alpha$, EGF, FGF and VEGF in the tumor microenvironment. Higher levels of these ligands activate RTK signaling in breast cancer as well as macrophages [125]. A strong correlation between EGFR expression and CD163+ macrophages were found in tamoxifen-resistant breast cancer patients [126]. Moreover, TAMs upregulate the cancer stemness associated genes along with increased drug efflux and chemoresistance in preclinical breast cancer model [127].

\section{Receptor tyrosine kinase (RTK)-targeted cancer therapeutics}

Breast cancer is a heterogeneous disease which has been characterized molecularly into five subtypes depending on expression of ER, PR and HER2. These subtypes consist of Luminal A (low grade, ER+/PR+, HER2-, low Ki67), Luminal B (ER+/PR+, HER2+ or HER2-, high Ki67), TNBC or basal-like (ER-/PR- and HER2-), HER2enriched and normal-like breast cancer [128]. For 
hormone receptor-positive breast cancer (luminal A and B), hormone therapy consists of selective estrogen receptor modulators (tamoxifen and raloxifene) is routinely used as adjuvant therapy [129]. Since TNBC or basallike and HER-enriched breast cancer do not express hormone receptors so that hormone therapy is not effective in these subtypes. However, due to the prominent expression of RTKs in TNBC and HER2-enriched subtypes, blocking the functions of RTKs is one of the promising approaches for management of TNBC and HER2-enriched breast cancer. So far, various strategies have been adopted for inhibition of RTK-dependent signaling. Mutations or overexpression of EGFR genes leads to tumor progression and drug resistance in various cancer types including breast [127]. Therefore, EGFR holds the potential to be an attractive drug target in breast cancer, and the EGFR inhibitors, including small molecule inhibitors and monoclonal antibodies (mAbs), have been developed and some are currently used in clinics. Overexpression of HER2 is frequently found in breast cancer. Several HER2-targeting drugs were developed and are currently used for the treatment of breast cancer.

Trastuzumab (Herceptin) is a humanized mAb which targets the extracellular domain of HER2 in HER2+ breast cancer and it has been reported to enhance survival of patients at early and late stages of breast cancer [130]. However, the exact mechanism through which trastuzumab exhibits its therapeutic effect is not well understood. De et al. have reported that trastuzumab inhibits HER2-HER3 heterodimerization which is known to occur in a ligand-independent manner in HER2+ breast cancer. Several reports also suggested that trastuzumab might induce HER2 degradation but the underlying mechanism is unexplored [131]. Although treatment with trastuzumab significantly improves disease outcome, resistance to trastuzumab is a major barrier to treat HER2-positive breast cancer. Approximately $65 \%$ of HER2-positive breast cancer patients do not respond to primary trastuzumab treatment. Moreover, a majority of patients those who originally respond well to trastuzumab therapy show tumor relapse later [132, 133]. In 2013, FDA approved an antibody-drug conjugate T-DM1 or trastuzumab emtansine or ado trastuzumab emtansine (trade name Kadcyla) for the treatment of HER-positive metastatic breast cancer patients who has been previously treated with trastuzumab and a taxane. T-DM1 consists of trastuzumab and cytotoxic agent emtansine (DM1) which kills the cancer cells by binding to tubulin [134]. A random trial on 991patients with HER2-positive advanced breast cancer showed higher median progression-free survival in TDM1-treated patients compared to lapatinib plus capecitabine-treated ones [135]. However, a recently completed phase III trial using trastuzumab plus taxane, T-DM1 plus placebo, T-DM1, or T-DM1 plus pertuzumab regimens at standard doses in 1095 HER2-positive advanced breast cancer patients. No significant increase in progression-free survival in T-DM1 and T-DM1 plus pertuzumab groups was observed as compared with trastuzumab plus taxane; although, T-DM1 containing arms showed better tolerability [136]. Pertuzumab (trade name perjeta) is another monoclonal antibody against HER2 which has been approved for neo-adjuvant or adjuvant therapy of HER2-positive advanced breast cancer in a combination with trastuzumab and docetaxel. Clinical trials have demonstrated that breast cancer patient's administered with combination of pertuzumab, trastuzumab and docetaxel had enhanced progression-free survival compared to control group [137, 138].

TNBC or basal-like breast cancer is known to be negative for HER2, shown to express EGFR in $40 \%$ of the patients, of those $18 \%$ of patients are reported to have amplified EGFR gene. Hence, EGFR is one of the important targets for HER2 negative breast cancer including TNBCs. Lapatinib (Tykerb), a dual tyrosine kinase inhibitor, binds to ATP binding pocket of EGFR and HER2 kinase domain and blocks ATP binding thereby leading to inhibition of EGFR and HER2 kinase activity. The tyrosine kinase inhibitors (TKIs) are known to be used as an alternate therapeutic regimen in HER2+ breast cancer patients with trastuzumab resistance $[139,140]$. Moreover, lapatinib has been used in combination with other anticancer drugs, capecitabine or letrozole. These combination therapies showed higher disease-free survival in HER2+ metastatic breast cancer patients [141, 142]. Multiple clinical trials have been conducted to assess the efficacy and toxicity of TKIs either alone or in combination with other drugs in breast cancer. Unfortunately, the outcomes of these trials have been disappointed so far. Few trials and their outcomes are enlisted in Table 2. Phase II clinical trials of gefitinib or erlotinib have shown poor overall response rate (ORR) while clinical trial with gefitinib in combination with epirubicin and cyclophosphamide showed no significant difference in pathologic complete response in ER-negative breast cancer [142-146]. Further, afatinib, a second-generation irreversible EGFR TKI, has shown no objective responses in phase II trial in metastatic TNBC patients [147].

There have been six clinical trials with anti-EGFR mAbs to explore their efficacy and safety in TNBC patients as given in Table 2. Carey et al. have performed a clinical trial in metastatic advanced recurrent breast cancer to examine the efficacy of cetuximab or cetuximab in combination with carboplatin. Cetuximab in combination with carboplatin demonstrated higher response rate as compared to carboplatin alone. However, 13 out of 
Table 2 Current anti-RTK therapy

\begin{tabular}{|c|c|c|c|c|}
\hline \multicolumn{5}{|c|}{ Clinical studies of RTK-targeted therapeutics in breast cancer } \\
\hline \multicolumn{2}{|l|}{ Molecule } & Target & Outcome & Ref. \\
\hline \multicolumn{2}{|c|}{$\begin{array}{l}\text { Gefitinib +Epirubicin and } \\
\text { Cyclophosphamide }\end{array}$} & EGFR & No significance & [146] \\
\hline \multicolumn{2}{|c|}{ Cetuximab + Carboplatin } & EGFR & $\begin{array}{l}\text { Overall response rate: } \\
6 \%(\text { Carb), 16\% } \\
\text { (Carb + cetux), } \\
\text { TTP - } 2.1 \text { month }\end{array}$ & [148] \\
\hline \multicolumn{2}{|c|}{ Cetuximab + Cisplatin } & EGFR & $\begin{array}{l}\text { Overall response rate: } \\
10 \% \text { (cis), } 20 \% \\
\text { (cis + cetux) P=0.032 }\end{array}$ & [149] \\
\hline \multicolumn{2}{|c|}{ Cetuximab + Ixabepilone } & EGFR & No significance & [150] \\
\hline \multicolumn{2}{|c|}{ Cetuximab + Irinotecan } & EGFR & $\begin{array}{l}\text { Overall response rate: } \\
11 \%\end{array}$ & [151] \\
\hline \multicolumn{2}{|c|}{$\begin{array}{l}\text { Panitumumab + Epirubicin, } \\
\text { Fluorouracil and } \\
\text { Cyclophosphamide (EFC) + } \\
\text { Docetaxal }\end{array}$} & EGFR & $\begin{array}{l}\text { Pathological complete } \\
\text { response: } 47 \%\end{array}$ & [152] \\
\hline \multicolumn{2}{|c|}{ Cetuximab + Docetaxal } & EGFR & $\begin{array}{l}\text { Pathological complete } \\
\text { response: } 24 \%\end{array}$ & [153] \\
\hline \multicolumn{2}{|c|}{$\begin{array}{l}\text { Panitumumab+Paclitaxal } \\
\text { and Carboplatin }\end{array}$} & EGFR & $\begin{array}{l}\text { Overall response rate: } \\
46 \%\end{array}$ & [154] \\
\hline \multicolumn{2}{|c|}{ Erlotinib + Bendamustine } & EGFR & $\begin{array}{l}\text { Cause excessive toxicity } \\
\text { with severe, prolonged } \\
\text { lymphopenia }\end{array}$ & [155] \\
\hline \multicolumn{2}{|c|}{ Paclitaxal + Bevacizumab } & VEGFR & $\begin{array}{l}\text { Higher progression free } \\
\text { survival }\end{array}$ & [156] \\
\hline \multicolumn{2}{|c|}{ Bevacizumab + Capacitabine } & VEGFR & $\begin{array}{l}\text { Higher progression free } \\
\text { survival }\end{array}$ & [157] \\
\hline \multicolumn{2}{|c|}{ Sunitinib + Docetaxal } & VEGFR, PDGFR & $\begin{array}{l}\text { No significant difference } \\
\text { in progression free survival }\end{array}$ & [158] \\
\hline \multicolumn{5}{|c|}{ Currently investigated clinical trials of targeting RTK in breast cancer } \\
\hline Molecule & Type & Target & Phase of study & Mechanism \\
\hline Trastuzumab & Humanized MAb & HER2 & In clinical use & $\begin{array}{l}\text { Inhibits HFR2 and HER3 } \\
\text { dimerization, induces } \\
\text { ADCC [159] }\end{array}$ \\
\hline Cetuximab & ChimaricMAb & EGFR & Phase I, II & $\begin{array}{l}\text { Enhances sensitivity to } \\
\text { DNA-damaging agents } \\
\text { in BRCA1-mutated and } \\
\text { PTEN-wild-type TNBC, } \\
\text { Induces NK cell mediated } \\
\text { ADCC }[160,161]\end{array}$ \\
\hline Panitumumab & Humanized MAb & EGFR & Phase II & $\begin{array}{l}\text { Enhances sensitivity to } \\
\text { DNA-damaging agents } \\
\text { in BRCA1-mutated and } \\
\text { PTEN-wild-type TNBC [161] }\end{array}$ \\
\hline Nimotuzumab & Humanized MAb & EGFR & Phase I & $\begin{array}{l}\text { Induces NK cell mediated } \\
\text { ADCC [162] }\end{array}$ \\
\hline Necitumumab & Humanized MAb & EGFR & Phase II & $\begin{array}{l}\text { Inhibits downstream targets } \\
\text { in EGFR pathway, induces } \\
\text { ADCC [163] }\end{array}$ \\
\hline Gefitinib & Reversible TKI & EGFR & Phase I, II & $\begin{array}{l}\text { Reverses TAM resistance by } \\
\text { up-regulating the ERa [164] }\end{array}$ \\
\hline Erlotinib & Reversible TKI & EGFR & Phase I, II & Suppresses CDK2 activity [165] \\
\hline Lapatinib & Reversible TKI & EGFR, HER2 & In clinical use & $\begin{array}{l}\text { Used as an alternate therapy } \\
\text { in trastuzumab resistant HER2 } \\
\text { positive breast cancer [139] }\end{array}$ \\
\hline
\end{tabular}


Table 2 Current anti-RTK therapy (Continued)

\begin{tabular}{|c|c|c|c|c|}
\hline \multicolumn{5}{|c|}{ Clinical studies of RTK-targeted therapeutics in breast cancer } \\
\hline Afatinib & Irreversible TKI & EGFR, HER2 & Phase II & $\begin{array}{l}\text { Inhibits EGFR and HER2 } \\
\text { signalling irreversibly [166] }\end{array}$ \\
\hline Varlitinib & Reversible TKI & EGFR, HER2, ErbB4 & Phase ॥ & $\begin{array}{l}\text { Inhbits HER/MAPK signalling } \\
\text { in TNBC [167] }\end{array}$ \\
\hline Dacomitinib & Irreversible TKl & EGFR, HER2, ErbB4 & Phase 1, Solid tumors & $\begin{array}{l}\text { Inhibits HER2, EGFR, HER4, } \\
\text { Akt and ERK phosphorylation } \\
\text { and show high antitumor } \\
\text { effect in trastuzumab and } \\
\text { lapatinib resistant HER2 } \\
\text { overexpressing breast } \\
\text { cancer [168] }\end{array}$ \\
\hline Sapitinib & Reversible TKI & EGFR, HER2, ErbB3 & Phase 1 , Solid tumors & $\begin{array}{l}\text { Showed higher inhibitory } \\
\text { potential in tamoxifen } \\
\text { resistant breast cancer [169] }\end{array}$ \\
\hline Vandetanib & TKI & EGFR, VEGFR2-3, RET & Phase I, II & $\begin{array}{l}\text { Targets angiogenesis by } \\
\text { inhibiting VEGFR2 and } 3 \\
\text { signalling along with EGFR } \\
\text { pathway [170] }\end{array}$ \\
\hline Neratinib & Irreversible TKI & EGFR, HER2, ErbB4 & Phase I, II, III & $\begin{array}{l}\text { Irreversibly blocks EGFR and } \\
\text { HER2 pathway [171] }\end{array}$ \\
\hline BMS-690514 & Irreversible TKl & $\begin{array}{l}\text { EGFR, HER2, ErbB4, } \\
\text { VEGFR1-3 }\end{array}$ & Phase 1, Solid tumors & $\begin{array}{l}\text { Irreversibly blocks EGFR and } \\
\text { HER2 pathway leading to } \\
\text { inhibition of their downstream } \\
\text { signaling pathways [172] }\end{array}$ \\
\hline AEE788 & Reversible TKI & EGFR, ErbB2, VEGFR & Phase I & $\begin{array}{l}\text { Targets angiogenesis by } \\
\text { inhibiting VEGFR2 and } 3 \\
\text { signalling along with EGFR } \\
\text { pathway [173] }\end{array}$ \\
\hline Lucitanib & TKI & $\begin{array}{l}\text { FGFR 1-2, VEGFR 1-3, } \\
\text { PDGFRa/ } \beta\end{array}$ & Phase II & $\begin{array}{l}\text { Show anti-angiogenic and } \\
\text { anti-tumoral activity by } \\
\text { targeting FGFR and VEGFR [174] }\end{array}$ \\
\hline
\end{tabular}

18 treated patients showed active EGFR signaling that indicates cetuximab failed to inhibit the EGFR pathway [148]. Higher response rate in cisplatin-cetuximab treated patients (20\%) as compared to cisplatintreated group (10\%) has been reported in advanced TNBC. However, the outcomes were not statistically significant [149]. Similarly, a phase II trial of ixabepilone alone and ixabepilone plus cetuximab in patients with advanced/metastatic TNBC was conducted by Tredan et al. This study has shown no improvement in response rate [150]. Meanwhile, irinotecan and cetuximab were shown increased response rate in TNBC patients compared to other subtypes, however, the results were not statistically significant [151]. Modest response was observed when operable TNBC patients were treated with standard FEC (5-fluorouracil, epidoxorubicin, and cyclophosphamide) following preoperative chemotherapy consisting of panitumumab or cetuximab combined with docetaxel [152, 153]. Higher CD8+ tumor infiltrating lymphocytes (TILs) were spotted in the tumor microenvironment in response to EGFR mAb neoadjuvant therapy. Overall, the outcome of clinical trials of EGFR mAbs in TNBC seems to be slightly better than that of EGFR
TKIs. Several trials using anti-RTK therapy and their outcomes are enlisted in Table 2 [146, 154-174].

\section{Challenges in targeting RTKs in breast cancer: emphasis on compensatory elements}

RTK-targeting therapeutic drugs are known to reduce multidrug resistance and CSC phenotype in breast cancer cells. However, cancer cells exhibit the resistance to RTK inhibitors in clinical and preclinical models. For example, HER2-targeted therapies (trastuzumab, pertuzumab, TDM1 and lapatinib) are known to impede primary tumor progression and cancer relapse but still drug resistance is observed in approximately $80 \%$ of HER2+ metastatic breast cancer patients [142]. Similarly, many cancer types including breast often acquire resistance to various RTK inhibitors such as VEGFR inhibitors (bevacizumab) [175], EGFR inhibitors (gefitinib) [176], FGFR inhibitors (AZD4547) [177]. Several mechanisms have been derived to describe the occurrence of resistance to RTK inhibitors. Several mutations in RTKs and their downstream targets and the activation of multiple other RTKs are the major compensatory elements instigated the survival pathways and resistance to anti-RTK therapies in breast cancer. IGF1R, EGFR, AXL, VEGFR 
are other RTK members share common downstream signaling molecules such as PI3K/Akt/mTOR and MAPK with HER2 in breast cancer [178]. Moreover, IGF1R overexpressed in HER2+ breast cancer and forms a heteromeric complex with HER2 and HER3 to activate PI3K signaling pathway. These heteromeric complex formation with HER family proteins have been associated with trastuzumab resistance in HER2+ metastatic breast cancer patients [179]. Combination of anti-HER2 drugs with antiIGF1R mAbs (metformin and figitumumab) have reported to produce synergetic effects in breast cancer cells. C-Met is the RTK, frequently expressed in HER2+ breast cancer patients and contributes to trastuzumab resistance. Upregulation of c-Met protects the cancer cells from trastuzumab via abrogating p27-induction whereas inhibition of c-Met sensitizes the cancer cells to trastuzumab treatment [180]. c-Src-mediated phosphorylation of EGFR at Tyr845, Tyr992, and Tyr1086 is associated with resistance to antiEGFR therapy in breast cancer. Activation of c-Met during EGFR treatment facilitates c-Src kinase-associated phosphorylation and cell growth in breast cancer cells. Furthermore, a combination of c-Met targeting small molecule inhibitors along with EGFR inhibitor decreases EGFR phosphorylation and kinase activity via inhibiting c-Src kinase thereby reduces the EGFR resistance [181]. Increased copy number of FGF3/4/19 has been reported in lapatinib and trastuzamab-resistant tumors. Higher expression and phosphorylation of FGFR is correlated with reduced disease-free survival and anti-HER2 therapy resistance in breast cancer patients. Activation of FGFR further stimulates the phosphorylation of non-receptor kinases such as MAPK and PI3K/Akt through the activation of phospholipase $\mathrm{C}_{\gamma}$ in tamoxifen-resistant breast cancer [182]. Amplifications and mutations in RTK dependent downstream target genes (PI3KCA or Akt) bypass the role of RTKs in their activation so that produce uninterrupted activation of growth signaling in breast cancer cells. Mutation in PI3CA is strongly associated with ErbB2-overexpression and lymph node metastasis [183].

Bevacizumab is the first anti-VEGFR drug approved by US FDA for the treatment of breast cancer but it is discontinued eventually due to the occurrence of resistance to it. Anti-VEGFR therapy induces hypoxia in the tumor microenvironment and its lead to increase in the aggressiveness of breast cancer. Under hypoxic stimuli, stromal cells secrete very high level of cytokines that activate alternate angiogenic pathways and increase the cancer stemness and autophagy [175]. Ephrin- A1 and B2 are proangiogenic factors, important for the remodeling and maturation of new blood vessels. Hypoxia mediates the upregulation of ephrin and the expression of ephrins is strongly associated with resistance to VEGFR therapy. Several proangiogenic factors such as angiopoietin 2 (ANG-2), EGF, bFGF, keratinocyte growth factor, IGF-1,
TGF- $\beta$, TNF- $\alpha$ and interleukins (IL-1, IL-8, IL-12 and IL-17) have been implicated in hypoxia-associated tumor refractoriness to anti-VEGFR therapy [184]. Secretion of IL-17, G-CSF, IL-6 and SDF1in tumor microenvironment recruits $C D 11 b+G r 1+$ myeloid cells to tumor and conferring Bv8-associated VEGFR-independent angiogenesis leads to resistance to anti-VEGFR therapy. Depletion of $\mathrm{CD} 11 \mathrm{~b}+\mathrm{Gr} 1+$ myeloid cell infiltration by Bv8 neutralizing antibodies sensitizes the cancer cells to VEGFR-targeted therapy [185].

Impaired interaction between anti-RTK agents and its respective receptor is another reason behind the development of resistance. This might be due to the higher existence of masking proteins in close proximity to the receptors, structural changes in the receptor and lack of expression of targeted domain. Mucin-4 and CD44 are the cell surface proteins overexpressed in trastuzumab resistant breast cancer patients. Expression of these proteins in close proximity to the HER2 epitope masks the interaction between trastuzumab and HER2 and increase the breast cancer growth $[186,187]$. On other hand, expression of a truncated version of HER2 overrides trastuzumab sensitivity in breast cancer. $\mathrm{p} 95^{\mathrm{HER} 2}$ forms heterodimer with HER3 protein and activates downstream signaling in a ligand-independent manner (Fig. 3) [188]. Eliyatkin et al. have shown that $28 \%$ of the patients who develop trastuzumab resistance have higher expression of $\mathrm{p} 95^{\mathrm{HER} 2}$. However, low level of $\mathrm{p} 95^{\mathrm{HER} 2}$ expression is found in trastuzumab-sensitive patients as well [189]. Moreover, mutations in HER2 could perturb the antibody recognition or physical interaction between drug and receptor. T798M mutation in HER2 showed increased autocatalytic activity and expression of EGFR ligands lead to 10-fold changes in IC50 of lapatinib in human breast cancer cells. Moreover, EGFR targeting antibody, cetuximab or lapatinib revert the trastuzumab resistance in these T798M specific cells [190]. Hanker et al. have shown that patients with HER $2^{\text {L869R }}$ mutation acquire secondary mutation at HER2 ${ }^{\mathrm{T} 798 \mathrm{I}}$ as subsequent response to neratinib treatment. Molecular modeling studies suggested that HER2 ${ }^{\mathrm{T} 798 \mathrm{I}}$ has increased isoleucine content in its protein structure and that reduces the binding between neratinib and HER2 [191].

\section{Conclusions}

Overexpression or dysregulation of RTKs in breast cancer cells leads to accelerated tumor growth, angiogenesis and metastasis through the activation of various downstream signaling pathways. RTKs play a key role in cancer stemness and drug resistance to various conventional anticancer therapies. Hence, targeting RTKs is one of the more promising approaches for the management of breast cancer. Many of RTK targeting drugs are in clinic for the treatment of breast cancer. However, 
resistance-driven by mutations in RTKs and alternate pathway activation limits the use of anti-RTK therapeutics for the treatment of metastatic breast cancer. The comprehensive mechanism underlying the resistance to anti-RTK therapy needs to be investigated to develop therapeutic regimens for successful treatment of anti-RTK therapy-resistant breast cancer.

\section{Abbreviations}

CSCs: Cancer stem cells; EGFRs: Epidermal growth factor receptors; FGFRs: Fibroblast growth factor receptors; FRS2: FGF receptor substrate 2; Gab1: Grb2-associated binder 1; IGFRs: Insulin-like growth factor receptors; IRS1: Insulin receptor substrate 1; JAK: Janus kinase; MAPK: Mitogen-activated protein kinase; NGF: Nerve growth factor; PDGFRs: Platelet-derived growth factor receptors; PI3K: Phosphoinositide 3-kinase; PTB: Phosphotyrosinebinding; RTKs: Receptor tyrosine kinases; SCF: Stem cell factor; SH2: Src homology 2; STAT: Signal transducer and activator of transcription; TKD: Tyrosine kinase domain; VEGFRs: Vascular endothelial growth factor receptors

\section{Acknowledgments}

The authors acknowledge Dr. Mahadeo Gorain for carefully reading the manuscript.

\section{Author Contributions}

$\mathrm{RB}, \mathrm{SD}, \mathrm{VPG}$ and $\mathrm{ASY}$ equally contributed for writing the manuscript. DK contributed portion of manuscript. GCK conceived and coordinated for entire writing of manuscript. All authors read and approved the final manuscript.

\section{Funding}

N/A

\section{Availability of data and materials}

N/A

\section{Ethics approval and consent to participate}

No human and animal subjects are implicated in this study.

\section{Consent for publication}

Consent was taken for publication from all the authors.

\section{Competing interests}

The authors declare no competing interests.

\section{Publisher's Note}

Springer Nature remains neutral with regard to jurisdictional claims in published maps and institutional affiliations.

\section{Author details}

'Laboratory of Tumor Biology, Angiogenesis and Nanomedicine Research, National Centre for Cell Science, SP Pune University Campus, Pune 411007, India. ${ }^{2}$ Department of Cancer Biology, The University of Texas MD Anderson Cancer Center, Houston, Texas 77054, USA.

Received: 14 October 2017 Accepted: 1 February 2018

Published online: 19 February 2018

\section{References}

1. Siegel RL, Miller KD, Jemal A. Cancer statistics, 2017. CA Cancer J Clin. 2017:67(1):7-30

2. Tomiguchi M, Yamamoto Y, Yamamoto-Ibusuki M, Goto-Yamaguchi L, Fujiki $Y$, Fujiwara S, et al. Fibroblast growth factor receptor-1 protein expression is associated with prognosis in estrogen receptor-positive/ human epidermal growth factor receptor-2-negative primary breast cancer. Cancer Sci. 2016;107(4):491-8.

3. Palmieri D, Bronder JL, Herring JM, Yoneda T, Weil RJ, Stark AM, et al. Her-2 overexpression increases the metastatic outgrowth of breast cancer cells in the brain. Cancer Res. 2007;67(9):4190-8.
4. Lemmon MA, Schlessinger J. Cell signaling by receptor tyrosine kinases. Cell. 2010;141(7):1117-34

5. Templeton AJ, Diez-Gonzalez L, Ace O, Vera-Badillo F, Šeruga B, Jordán $J$, et al. Prognostic relevance of receptor tyrosine kinase expression in breast cancer: a meta-analysis. Cancer Treat Rev. 2014;40(9):1048-55.

6. Wise R, Zolkiewska A. Metalloprotease-dependent activation of EGFR modulates CD44+/CD24- populations in triple negative breast cancer cells through the MEK/ERK pathway. Breast Cancer Res Treat. 2017; 166(2):421-3.

7. Park J, Kim S, Joh J, Remick SC, Miller DM, Yan J, et al. MLLT11/AF1q boosts oncogenic STAT3 activity through Src-PDGFR tyrosine kinase signaling. Oncotarget. 2016;7(28):43960.

8. Qian BZ, Zhang H, Li J, He T, Yeo EJ, Soong DY, et al. FLT1 signaling in metastasis-associated macrophages activates an inflammatory signature that promotes breast cancer metastasis. J Exp Med. 2015;212(9):1433-48.

9. Ibrahim SA, Gadalla R, El-Ghonaimy EA, Samir O, Mohamed HT, Hassan H, et al. Syndecan-1 is a novel molecular marker for triple negative inflammatory breast cancer and modulates the cancer stem cell phenotype via the IL-6/ STAT3, Notch and EGFR signaling pathways. Mol Cancer. 2017;16(1):57.

10. Zhao D, Pan C, Sun J, Gilbert C, Drews-Elger K, Azzam DJ, et al. VEGF drives cancer-initiating stem cells through VEGFR-2/Stat3 signaling to upregulate Myc and Sox2. Oncogene. 2015;34(24):3107-19.

11. Bussard KM, Mutkus L, Stumpf K, Gomez-Manzano C, Marini FC. Tumorassociated stromal cells as key contributors to the tumor microenvironment. Breast Cancer Res. 2016;18(1):84.

12. Plantamura I, Casalini P, Dugnani E, Sasso M, D'ippolito E, Tortoreto M, et al. PDGFRß and FGFR2 mediate endothelial cell differentiation capability of triple negative breast carcinoma cells. Mol Oncol. 2014;8(5):968-81.

13. D'Ippolito E, Plantamura I, Bongiovanni L, Casalini P, Baroni S, Piovan C, et al. miR-9 and miR-200 regulate PDGFRß-mediated endothelial differentiation of tumor cells in triple-negative breast cancer. Cancer Res. 2016;76(18):5562-72.

14. He M, Wei MJ. Reversing multidrug resistance by tyrosine kinase inhibitors. Chin J Cancer. 2012;31(3):126-13.

15. Huang L, Fu L. Mechanisms of resistance to EGFR tyrosine kinase inhibitors. Acta Pharm Sin B. 2015:5(5):390-401.

16. Shrivastava A, Radziejewski C, Campbell E, Kovac L, McGlynn M, Ryan TE, et al. An orphan receptor tyrosine kinase family whose members serve as nonintegrin collagen receptors. Mol Cell. 1997;1 (1):25-34.

17. Clayton AH, Walker F, Orchard SG, Henderson C, Fuchs D, Rothacker J, et al. Ligand-induced dimer-tetramer transition during the activation of the cell surface epidermal growth factor receptor-A multidimensional microscopy analysis. J Biol Chem. 2005;280(34):30392-9.

18. Ward CW, Lawrence MC, Streltsov VA, Adams TE, McKern NM. The insulin and EGF receptor structures: new insights into ligand-induced receptor activation. Trends Biochem Sci. 2007;32(3):129-37.

19. Wiesmann C, Ultsch MH, Bass SH, de Vos AM. Crystal structure of nerve growth factor in complex with the ligand-binding domain of the TrkA receptor. Nature. 1999:401(6749):184-8.

20. Wehrman T, He X, Raab B, Dukipatti A, Blau H, Garcia KC. Structural and mechanistic insights into nerve growth factor interactions with the TrkA and p75 receptors. Neuron. 2007;53(1):25-38.

21. Burgess AW, Cho HS, Eigenbrot C, Ferguson KM, Garrett TP, Leahy DJ, et al. An open-and-shut case?Recent insights into the activation of EGF/ErbB receptors. Mol Cell. 2003;12(3):541-52

22. Yuzawa S, Opatowsky Y, Zhang Z, Mandiyan V, Lax I, Schlessinger J. Structural basis for activation of the receptor tyrosine kinase KIT by stem cell factor. Cell. 2007;130(2):323-34.

23. Schlessinger J, Plotnikov AN, Ibrahimi OA, Eliseenkova AV, Yeh BK, Yayon A, et al. Crystal structure of a ternary FGF-FGFR-heparin complex reveals a dual role for heparin in FGFR binding and dimerization. Mol Cell. 2000;6(3):743-50.

24. Huse M, Kuriyan J. The conformational plasticity of protein kinases. Cell. 2002;109(3):275-82.

25. Hubbard SR. Juxtamembrane autoinhibition in receptor tyrosine kinases. Nat Rev Mol Cell Biol. 2004;5(6):464-71.

26. Griffith J, Black J, Faerman C, Swenson L, Wynn M, Lu F, et al. The structural basis for autoinhibition of FLT3 by the juxtamembrane domain. Mol Cell. 2004;13(2):169-78

27. Till JH, Becerra M, Watty A, Lu Y, Ma Y, Neubert TA, et al. Crystal structure of the MuSK tyrosine kinase: insights into receptor autoregulation. Structure. 2002;10(9):1187-96. 
28. Mol CD, Dougan DR, Schneider TR, Skene RJ, Kraus ML, Scheibe DN, et al. Structural basis for the autoinhibition and STI-571 inhibition of c-Kit tyrosine kinase. J Biol Chem. 2004;279(30):31655-63.

29. Pawson T. Dynamic control of signaling by modular adaptor proteins. Curr Opin Cell Biol. 2007;19(2):112-6.

30. Harris RC, Chung E, Coffey RJ. EGF receptor ligands. In: Carpenter G, editor. The EGF receptor family biologic mechanisms and role in cancer. California: Elsevier; 2004. p. 3-14.

31. Freed DM, Bessman NJ, Kiyatkin A, Salazar-Cavazos E, Byrne PO, Moore JO, et al. EGFR ligands differentially stabilize receptor dimers to specify signaling kinetics. Cell. 2017;171(3):683-95.

32. Hu H, Liu Y, Jiang T. Mutation-introduced dimerization of receptor tyrosine kinases: from protein structure aberrations to carcinogenesis. Tumour Biol. 2015;36(3):1423-8

33. van Rhijn BW, van Tilborg AA, Lurkin I, Bonaventure J, de Vries A, Thiery JP, et al. Novel fibroblast growth factor receptor 3 (FGFR3) mutations in bladder cancer previously identified in non-lethal skeletal disorders. Eur J Hum Genet. 2002;10(12):819-24

34. Wagner JP, Wolf-Yadlin A, Sevecka M, Grenier JK, Root DE, Lauffenburger DA, et al. Receptor tyrosine kinases fall into distinct classes based on their inferred signaling networks. Sci Signal. 2013;6(284):ra58.

35. Al-Hajj M, Wicha MS, Benito-Hernandez A, Morrison SJ, Clarke MF. Prospective identification of tumorigenic breast cancer cells. Proc Nat AcadSci USA. 2003;100(7):3983-8.

36. Ginestier C, Hur MH, Charafe-Jauffret E, Monville F, Dutcher J, Brown M, et al. ALDHI is a marker of normal and malignant human mammary stem cells and a predictor of poor clinical outcome. Cell Stem Cell. 2007;1(5):555-67.

37. Liu S, Cong Y, Wang D, Sun Y, Deng L, Liu Y, et al. Breast Cancer Stem Cells Transition between Epithelial and Mesenchymal States Reflective of their Normal Counterparts. Stem Cell Rep. 2013;2(1):78-91.

38. Shibuya M. Vascular endothelial growth factor (VEGF) and its receptor (VEGFR) signaling in angiogenesis: a crucial target for anti-and proangiogenic therapies. Genes Cancer. 2011;2(12):1097-105.

39. Yu F, Yao H, Zhu P, Zhang X, Pan Q, Gong C, et al. let-7 regulates self renewal and tumorigenicity of breast cancer cells. Cell. 2007;131:1109-23.

40. Tanei T, Morimoto K, Shimazu K, Kim SJ, Tanji Y, Taguchi T, et al. Association of breast cancer stem cells identified by aldehyde dehydrogenase 1 expression with resistance to sequential Paclitaxel and epirubicin-based chemotherapy for breast cancers. Clin Cancer Res. 2009;15(12):4234-41.

41. Nakayama A, Takagi S, Yusa T, Yaguchi M, Hayashi A, Tamura T, et al. Antitumor activity of TAK-285, an investigational, non-Pgp substrate HER2/ EGFR kinase inhibitor, in cultured tumor cells, mouse and rat xenograft tumors, and in an HER2-positive brain metastasis model. J Cancer. 2013;4(7):557-65.

42. Mayer A, Takimoto M, Fritz E, Schellander G, Kofler K, Ludwig H. The prognostic significance of proliferating cell nuclear antigen, epidermal growth factor receptor, and mdr gene expression in colorectal cancer. Cancer. 1993;71(8):2454-60.

43. Jin $Y$, Zhang $W$, Xu J, Wang H, Zhang Z, Chu C, et al. UCH-L1 involved in regulating the degradation of EGFR and promoting malignant properties in drug-resistant breast cancer. Int J Clin Exp Pathol. 2015; 8(10):12500-8

44. Lee HJ, Seo AN, Kim EJ, Jang MH, Kim YJ, Kim JH, et al. Prognostic and predictive values of EGFR overexpression and EGFR copy number alteration in HER2-positive breast cancer. Br J Cancer. 2015;112(1): 103-11.

45. Park HS, Jang MH, Kim EJ, Kim HJ, Lee HJ, Kim YJ, et al. High EGFR gene copy number predicts poor outcome in triple-negative breast cancer. Mod Pathol. 2014;27(9):1212-22.

46. Wilson KJ, Gilmore JL, Foley J, Lemmon MA, Riese DJ. Functional selectivity of EGF family peptide growth factors: implications for cancer. Pharmaco Ther. 2009;122(1):1-8.

47. Macdonald-Obermann JL, Pike $\sqcup$. Different epidermal growth factor (EGF) receptor ligands show distinct kinetics and biased or partial agonism for homodimer and heterodimer formation. J Biol Chem. 2014;289(38):26178-88

48. Witton CJ, Reeves JR, Going JJ, Cooke TG, Bartlett J. Expression of the HER1-4 family of receptor tyrosine kinases in breast cancer. J Pathol. 2003;200(3):290-7

49. Price JT, Tiganis T, Agarwal A, Djakiew D, Thompson EW. Epidermal growth factor promotes MDA-MB-231 breast cancer cell migration through a phosphatidylinositol 3'-kinase and phospholipase Cdependent mechanism. Cancer Res. 1999;59(21):5475-8.
50. Silva CM. Role of STATs as downstream signal transducers in Src family kinase-mediated tumorigenesis. Oncogene. 2004:23(48):8017-23.

51. Zheng Z, Shao N, Weng H, Li W, Zhang J, Zhang L, et al. Correlation between epidermal growth factor receptor and tumor stem cell markers CD44/CD24 and their relationship with prognosis in breast invasive ductal carcinoma. Med Oncol. 2015:32(1):275.

52. Hance KW, Anderson WF, Devesa SS, Young HA, Levine PH. Trends in inflammatory breast carcinoma incidence and survival: the surveillance, epidemiology, and end results program at the National Cancer Institute. J Natl Cancer Inst. 2005;97(13):966-75.

53. Charafe-Jauffret E, Ginestier C, lovino F, Tarpin C, Diebel M, Esterni B, et al. Aldehyde dehydrogenase 1-Positive cancer stem cells mediate metastasis and poor clinical outcome in inflammatory breast cancer. Clin Cancer Res. 2010;16(1):45-55

54. Van Laere SJ, Van der Auwera I, Van den Eynden GG, Van Dam P, Van Marck EA, Vermeulen PB, et al. NF-KB activation in inflammatory breast cancer is associated with oestrogen receptor downregulation, secondary to EGFR and/or ErbB2 overexpression and MAPK hyperactivation. Br J Cancer. 2007; 97(5):659-69.

55. Wang X, Reyes ME, Zhang D, Funakoshi Y, Trape AP, Gong Y, et al. EGFR signaling promotes inflammation and cancer stem-like activity in inflammatory breast cancer. Oncotarget. 2017;8(40):67904-17.

56. Tian M, Schiemann WP. TGF- $\beta$ stimulation of EMT programs elicits nongenomic ER-a activity and anti-estrogen resistance in breast cancer cells. Cancer Metastasis Treat. 2017;3:150-60.

57. Yeo SK, Wen J, Chen S, Guan JL. Autophagy differentially regulates distinct breast cancer stem-like cells in murine models via EGFR/Stat3 and TgfB/ Smad signaling. Cancer Res. 2016;76(11):3397-410.

58. Holdman XB, Welte T, Rajapakshe K, Pond A, Coarfa C, Mo Q, et al. Upregulation of EGFR signaling is correlated with tumor stroma remodeling and tumor recurrence in FGFR1-driven breast cancer. Breast Cancer Res. 2015:17(1):141.

59. Yang J, Liao D, Chen C, Liu Y, Chuang TH, Xiang R, et al. Tumorassociated macrophages regulate murine breast cancer stem cells through a novel paracrine EGFR/Stat3/Sox-2 signaling pathway. Stem Cells. 2013;31(2):248-58.

60. Alitalo K, Carmeliet P. Molecular mechanisms of lymphangiogenesis in health and disease. Cancer Cell. 2002;1(3):219-27.

61. Laakkonen P, Waltari M, Holopainen T, Takahashi T, Pytowski B, Steiner P, et al. Vascular endothelial growth factor receptor 3 is involved in tumor angiogenesis and growth. Cancer Res. 2007;67(2):593-9.

62. Chakraborty G, Jain S, Kundu GC. Osteopontin promotes vascular endothelial growth factor-dependent breast tumor growth and angiogenesis via autocrine and paracrine mechanisms. Cancer Res. 2008;68(1):152-61.

63. Srabovic N, Mujagic Z, Mujanovic-Mustedanagic J, Softic A, Muminovic Z, Rifatbegovic A, et al. Vascular endothelial growth factor receptor-1 expression in breast cancer and its correlation to vascular endothelial growth factor a. Int J Breast Cancer. 2013;2013:746749.

64. Kosaka Y, Kataoka A, Yamaguchi H, Ueo H, Akiyoshi S, Sengoku N, et al. Vascular endothelial growth factor receptor-1 mRNA overexpression in peripheral blood as a useful prognostic marker in breast cancer. Breast Cancer Res. 2012;14(5):R140.

65. Kapahi R, Guleria K, Sambyal V, Manjari M, Sudan M, Uppal MS, et al. Association of VEGF and VEGFR1 polymorphisms with breast cancer risk in North Indians. Tumour Biol. 2015;36(6):4223-34.

66. Ning Q, Liu C, Hou L, Meng M, Zhang X, Luo M, et al. Vascular endothelial growth factor receptor-1 activation promotes migration and invasion of breast cancer cells through epithelial-mesenchymal transition. PLoS One. 2013;8(6):e65217.

67. Incio J, Tam J, Rahbari NN, Suboj P, McManus DT, Chin SM, et al. PIGF/ VEGFR-1 signaling promotes macrophage polarization and accelerated tumor progression in obesity. Clin Cancer Res. 2016;22(12):2993-3004.

68. Chen XW, Yu TJ, Zhang J, Li Y, Chen HL, Yang GF, et al. CYP4A in tumorassociated macrophages promotes pre-metastatic niche formation and metastasis. Oncogene. 2017;36(35):5045-57.

69. Guo S, Colbert LS, Fuller M, Zhang Y, Gonzalez-Perez RR. Vascular endothelial growth factor receptor-2 in breast cancer. Biochim Biophys Acta. 2010:1806(1):108-21.

70. Pfister NT, Fomin V, Regunath K, Zhou JY, Zhou W, Silwal-Pandit L, et al. Mutant p53 cooperates with the SWI/SNF chromatin remodeling complex to regulate VEGFR2 in breast cancer cells. Genes Dev. 2015;29(12):1298-315. 
71. Jahangiri A, Nguyen A, Chandra A, Sidorov MK, Yagnik G, Rick J, et al. Crossactivating c-Met/ $\beta 1$ integrin complex drives metastasis and invasive resistance in cancer. Proc Natl Acad Sci. 2017;114(41):E8685-94.

72. Schoppmann SF, Bayer G, Aumayr K, Taucher S, Geleff S, Rudas M, et al. Prognostic value of lymphangiogenesis and lymphovascular invasion in invasive breast cancer. Ann Surg. 2004;240(2):306-12.

73. Tutunea-Fatan E, Majumder M, Xin X, Lala PK. The role of CCL21/CCR7 chemokine axis in breast cancer-induced lymphangiogenesis. Mol Cancer. 2015;14(1):35.

74. Timoshenko AV, Chakraborty C, Wagner GF, Lala PK. COX-2-mediated stimulation of the lymphangiogenic factor VEGF-C in human breast cancer. Br J Cancer. 2006;94(8):1154-63.

75. Lyons TR, Borges VF, Betts CB, Guo Q, Kapoor P, Martinson HA, et al. Cyclooxygenase-2-dependent lymphangiogenesis promotes nodal metastasis of postpartum breast cancer. J Clin Invest. 2014;124(9):3901-12.

76. Chen WS, Cao Z, Sugaya S, Lopez MJ, Sendra VG, Laver N, et al. Pathological lymphangiogenesis is modulated by galectin-8-dependent crosstalk between podoplanin and integrin-associated VEGFR-3. Nat Commun. 2016;7:11302.

77. Heldin $\mathrm{CH}$. Targeting the PDGF signaling pathway in tumor treatment. Cell Commun Signal. 2013;11(1):97.

78. Carvalho I, Milanezi F, Martins A, Reis RM, Schmitt F. Overexpression of platelet-derived growth factor receptor a in breast cancer is associated with tumour progression. Breast Cancer Res. 2005;7(5):R788-95.

79. Bhardwaj B, Klassen J, Cossette N, Sterns E, Tuck A, Deeley R, et al. Localization of platelet-derived growth factor beta receptor expression in the periepithelial stroma of human breast carcinoma. Clin Cancer Res. 1996; 2(4):773-82.

80. Paulsson J, Sjöblom T, Micke P, Pontén F, Landberg G, Heldin CH, et al. Prognostic significance of stromal platelet-derived growth factor $\beta$ receptor expression in human breast cancer. Am J Pathol. 2009;175(1): 334-41.

81. Pinto MP, Dye WW, Jacobsen BM, Horwitz KB. Malignant stroma increases luminal breast cancer cell proliferation and angiogenesis through platelet-derived growth factor signaling. BMC Cancer. 2014; 14(1):735

82. Plotnikov AN, Schlessinger J, Hubbard SR, Mohammadi M. Structural basis for FGF receptor dimerization and activation. Cell. 1999;98(5):641-50.

83. Tenhagen $M$, van Diest PJ, Ivanova IA, van der Wall $E$, van der Groep P. Fibroblast growth factor receptors in breast cancer: expression, downstream effects, and possible drug targets. Endocr Relat Cancer. 2012;19(4):R115-29.

84. Babina IS, Turner NC. Advances and challenges in targeting FGFR signalling in cancer. Nat Rev Cancer. 2017;17(5):318-32.

85. Courjal F, Cuny M, Simony-Lafontaine J, Louason G, Speiser P, Zeillinger R, et al. Mapping of DNA amplifications at 15 chromosomal localizations in 1875 breast tumors: definition of phenotypic groups. Cancer Res. 1997; 57(19):4360-7.

86. Brunello E, Brunelli M, Bogina G, Caliò A, Manfrin E, Nottegar A, et al. FGFR-1 amplification in metastatic lymph-nodal and haematogenous lobular breast carcinoma. J Exp Clin Cancer Res. 2012;31(1):103.

87. Hunter DJ, Kraft P, Jacobs KB, Cox DG, Yeager M, Hankinson SE, et al. A genome-wide association study identifies alleles in FGFR2 associated with risk of sporadic postmenopausal breast cancer. Nat Genet. 2007; 39(7):870-4.

88. Formisano L, Stauffer KM, Young CD, Bhola NE, Guerrero-Zotano AL, Jansen VM, et al. Association of FGFR1 with ERa maintains ligandindependent ER transcription and mediates resistance to estrogen deprivation in ER+ breast cancer. Clin Cancer Res. 2017;23(20): 6138-50.

89. Marian C, Ochs-Balcom HM, Nie J, Kallakury BV, Ambrosone CB, Trevisan $M$, et al. FGFR2 intronic SNPs and breast cancer risk: associations with tumor characteristics and interactions with exogenous exposures and other known breast cancer risk factors. Int J Cancer. 2011;129(3):702-12.

90. Cerliani JP, Guillardoy T, Giulianelli S, Vaque JP, Gutkind JS, Vanzulli SI, et al. Interaction between FGFR-2, STAT5 and progesterone receptors in breast cancer. Cancer Res. 2011;71(10):3720-31.

91. Cerliani JP, Vanzulli SI, Piñero CP, Bottino MC, Sahores A, Nuñez M, et al. Associated expressions of FGFR-2 and FGFR-3: from mouse mammary gland physiology to human breast cancer. Breast Cancer Res Treat. 2012;133(3): 997-1008.
92. Johnston CL, Cox HC, Gomm JJ, Coombes RC. Fibroblast growth factor receptors (FGFRs) localize in different cellular compartments A splice variant of FGFR-3 localizes to the nucleus. J Biol Chem. 1995;270(51): 30643-50.

93. Koziczak M, Hynes NE. Cooperation between fibroblast growth factor receptor-4 and ErbB2 in regulation of cyclin D1 translation. J Biol Chem. 2004;279(48):50004-11.

94. Brown WS, Akhand SS, Wendt MK. FGFR signaling maintains a drug persistent cell population following epithelial-mesenchymal transition. Oncotarget. 2016;7(50):83424-36.

95. Tan S, Ding K, Chong QY, Zhao J, Liu Y, Shao Y, et al. Decreased miR26a/b and increased HuR expression post-transcriptionally upregulates ERBB2 to mediate acquired tamoxifen resistance in ER+ breast cancer cells. J Biol Chem. 2017;292(33):13551-64.

96. Wang $Y$, Zhang $X$, Chao Z, Kung HF, Lin MC, Dress A, et al. MiR-34a modulates ErbB2 in breast cancer. Cell Biol Int. 2017;41(1):93-101.

97. He X-H, Zhu W, Yuan P, Jiang S, Li D, Zhang HW, et al. miR-155 downregulates ErbB2 and suppresses ErbB2-induced malignant transformation of breast epithelial cells. Oncogene. 2016;35(46):6015-25.

98. Du WW, Fang L, Li M, Yang X, Liang Y, Peng C, et al. MicroRNA miR-24 enhances tumor invasion and metastasis by targeting PTPN9 and PTPRF to promote EGF signaling. J Cell Sci. 2013;126:1440-53.

99. Choi BH, Ryu DY, Ryoo IG, Kwak MK. NFE2L2/NRF2 silencing-inducible miR206 targets c-MET/EGFR and suppresses BCRP/ABCG2 in cancer cells. Oncotarget. 2017;8(63):107188-205.

100. Vennin C, Spruyt N, Dahmani F, Julien S, Bertucci F, Finetti P, et al. H19 non coding RNA-derived miR-675 enhances tumorigenesis and metastasis of breast cancer cells by downregulating c-Cbl and Cbl-b. Oncotarget. 2015; 6(30):29209-23.

101. Van Grembergen O, Bizet M, de Bony EJ, Calonne E, Putmans P, Brohee S, et al. Portraying breast cancer with long noncoding RNAs. Sci Adv. 2016;2(9): e1600220.

102. Godinho MF, Sieuwerts AM, Look MP, Meijer D, Foekens JA, Dorssers LC, et al. Relevance of BCAR4 in tamoxifen resistance and tumor aggressiveness of human breast cancer. Br J Cancer. 2010;130(8):1284-91.

103. Massarweh S, Osborne CK, Creighton CJ, Qin L, Tsimelzon A, Huang S, et al. Tamoxifen resistance in breast tumors is driven by growth factor receptor signaling with repression of classic estrogen receptor genomic function. Cancer Res. 2008;68(3):826-33.

104. Osborne CK, Schiff R. Mechanisms of endocrine resistance in breast cancer. Annu Rev Med. 2011;62:233-47.

105. Ring A, Dowsett M. Mechanisms of tamoxifen resistance. Endocr Relat Cancer. 2004;11(4):643-58.

106. Schiff R, Massarweh SA, Shou J, Bharwani L, Mohsin SK, Osborne CK. Cross-talk between estrogen receptor and growth factor pathways as a molecular target for overcoming endocrine resistance. Clin Cancer Res. 2004;10(1):331s-6s.

107. García-Becerra R, Santos N, Díaz L, Camacho J. Mechanisms of resistance to endocrine therapy in breast cancer: focus on signaling pathways, miRNAs and genetically based resistance. Int J Mol Sci. 2012;14(1):108-45.

108. O'Brien CS, Howell SJ, Farnie G, Clarke RB. Resistance to endocrine therapy: are breast cancer stem cells the culprits? J Mammary Gland Biol Neoplasia. 2009;14(1):45-54.

109. Hiscox S, Baruah B, Smith C, Bellerby R, Goddard L, Jordan N, et al. Overexpression of CD44 accompanies acquired tamoxifen resistance in MCF7 cells and augments their sensitivity to the stromal factors, heregulin and hyaluronan. BMC Cancer. 2012;12(1):458.

110. Eyler CE, Rich JN. Survival of the fittest: cancer stem cells in therapeutic resistance and angiogenesis. J Clin Oncol. 2008;26(17):2839-45.

111. Bao B, Mitrea C, Wijesinghe P, Marchetti L, Girsch E, Farr RL, et al. Treating triple negative breast cancer cells with erlotinib plus a select antioxidant overcomes drug resistance by targeting cancer cell heterogeneity. Sci Rep. 2017;7:44125.

112. Robinson DR, Wu YM, Vats P, Su F, Lonigro RJ, Cao X, et al. Activating ESR1 mutations in hormone-resistant metastatic breast cancer. Nat Genet. 2013; 45(12):1446-51.

113. Fu H, Fu L, Xie C, Zuo WS, Liu YS, Zheng MZ, et al. miR-375 inhibits cancer stem cell phenotype and tamoxifen resistance by degrading HOXB3 in human ER-positive breast cancer. Oncol Rep. 2017;37(2):1093-9.

114. Jin K, Sukumar S. A pivotal role for HOXB7 protein in endocrine resistant breast cancer. Oncoscience. 2015;2(11):917-9. 
115. Angus SP, Zawistowski JS, Johnson GL. Epigenetic Mechanisms Regulating Adaptive Responses to Targeted Kinase Inhibitors in Cancer. Annu Rev Pharmacol Toxicol. 2018;58:209-29.

116. Nagalingam A, Tighiouart $M$, Ryden L, Joseph L, Landberg G, Saxena NK, et al. Med1 plays a critical role in the development of tamoxifen resistance. Carcinogenesis. 2012;33(4):918-30.

117. Cui J, Germer K, Wu T, Wang J, Luo J, Wang SC, et al. Cross-talk between HER2 and MED1 regulates tamoxifen resistance of human breast cancer cells. Cancer Res. 2012;72(21):5625-34.

118. Zelek L, Barthier S, Riofrio M, Fizazi K, Rixe O, Delord JP, et al. Weekly vinorelbine is an effective palliative regimen after failure with anthracyclines and taxanes in metastatic breast carcinoma. Cancer. 2001;92(9):2267-72.

119. Rebucci M, Michiels C. Molecular aspects of cancer cell resistance to chemotherapy. Biochem Pharmacol. 2013;85(9):1219-26.

120. Poole CJ, Earl HM, Hiller L, Dunn JA, Bathers S, Grieve RJ, et al. Epirubicin and cyclophosphamide, methotrexate, and fluorouracil as adjuvant therapy for early breast cancer. N Engl J Med. 2006;355(18):1851-62

121. Giuliano M, Giordano A, Jackson S, Hess KR, De Giorgi U, Mego M, et al. Circulating tumor cells as prognostic and predictive markers in metastatic breast cancer patients receiving first-line systemic treatment. Breast Cancer Res. 2011;13(3):R67.

122. Wu J, Lee $C$, Yokom D, Jiang $H$, Cheang MC, Yorida $E$, et al. Disruption of the $Y$-box binding protein-1 results in suppression of the epidermal growth factor receptor and HER-2. Cancer Res. 2006;66(9):4872-9.

123. Chen Y, Simon SM. In situ biochemical demonstration that P-glycoprotein is a drug efflux pump with broad specificity. J Cell Biol. 2000;148(5):863-70.

124. Sinnberg T, Sauer B, Holm P, Spangler B, Kuphal S, Bosserhoff A, et al. MAPK and PI3K AKT mediated YB-1 activation promotes melanoma cell proliferation which is counteracted by an autoregulatory loop. Exp Dermatol. 2012;21(4):265-70.

125. Lin EY, Pollard JW. Tumor-associated macrophages press the angiogenic switch in breast cancer. Cancer Res. 2007;67(11):5064-6.

126. Xuan QJ, Wang JX, Nanding A, Wang ZP, Liu H, Lian X, et al. Tumorassociated macrophages are correlated with tamoxifen resistance in the postmenopausal breast cancer patients. Pathol Oncol Res. 2014;20(3):619-24.

127. Rimawi MF, Shetty PB, Weiss HL, Schiff R, Osborne CK, Chamness GC, et al. Epidermal growth factor receptor expression in breast cancer association with biologic phenotype and clinical outcomes. Cancer. 2010;116(5):1234-42.

128. Dai X, Li T, Bai Z, Yang Y, Liu X, Zhan J, et al. Breast cancer intrinsic subtype classification, clinical use and future trends. Am J Cancer Res. 2015;5(10): 2929.

129. Mirkin S, Pickar JH. Selective estrogen receptor modulators (SERMs): a review of clinical data. Maturitas. 2015;80(1):52-7.

130. Hudis CA. Trastuzumab-Mechanism of action and use in clinical practice. N Engl J Med. 2007;357(1):39-51.

131. Emde A, Kostler WJ, Yarden Y. Therapeutic strategies and mechanisms of tumorigenesis of HER2-overexpressing breast cancer. Crit Rev Oncol Hematol. 2012:84(1):e49-57.

132. Ahmad S, Gupta S, Kumar R, Varshney GC, Raghava GPS. Herceptin resistance database for understanding mechanism of resistance in breast cancer patients. Sci Rep. 2014;4:4483.

133. Vu T, Sliwkowski MX, Claret FX. Personalized drug combinations to overcome trastuzumab resistance in HER2-positive breast cancer. Biochim Biophys Acta. 2014;1846(2):353-65.

134. Teicher BA, Doroshow JH. The promise of antibody-drug conjugates. N Engl J Med. 2012;367(19):1847-8.

135. Verma S, Miles D, Gianni L, Krop IE, Welslau M, Baselga J, et al. Trastuzumabemtansine for HER2-positive advanced breast cancer. N Engl J Med. 2012;367(19):1783-91.

136. Perez EA, Barrios C, Eiermann W, Toi M, Im YH, Conte $P$, et al. Trastuzumabemtansine with or without pertuzumab versus trastuzumab plus taxane for human epidermal growth factor receptor 2-positive advanced breast cancer: primary results from the phase III MARIANNE study. J Clin Oncol. 2017;35(2):141-8.

137. Baselga J, Cortés J, Kim SB, Im SA, Hegg R, Im YH, et al. Pertuzumab plus trastuzumab plus docetaxel for metastatic breast cancer. N Engl J Med. 2012;366(2):109-19.

138. Swain SM, Baselga J, Kim SB, Ro J, Semiglazov V, Campone M, et al. Pertuzumab, trastuzumab, and docetaxel in HER2-positive metastatic breast cancer. N Engl J Med. 2015;372(8):724-34.
139. Moreira C, Kaklamani V. Lapatinib and breast cancer: current indications and outlook for the future. Expert Rev Anticancer Ther. 2010;10(8):1171-82.

140. Blackwell KL, Burstein HJ, Storniolo AM, Rugo H, Sledge G, Koehler M. Randomized study of Lapatinib alone or in combination with trastuzumab in women with ErbB2-positive, trastuzumab-refractory metastatic breast cancer. J Clin Oncol. 2010;28(7):1124-30.

141. Johnston S, Pippen J Jr, Pivot X, Lichinitser M, Sadeghi S, Dieras V, et al. Lapatinib combined with letrozole versus letrozole and placebo as first-line therapy for postmenopausal hormone receptor-positive metastatic breast cancer. J Clin Oncol. 2009;27(33):5538-46.

142. Geyer CE, Forster J, Lindquist D, Chan S, Romieu CG, Pienkowski T, et al. Lapatinib plus capecitabine for HER2-positive advanced breast cancer. N Engl J Med. 2006;355(26):2733-43.

143. von Minckwitz G, Jonat W, Fasching P, du Bois A, Kleeberg U, Luck HJ, et al. A multicentre phase II study on gefitinib in tax $\neg$ ane- and anthracycline-pretreated metastatic breast cancer. Breast Cancer Res Treat. 2005;89(2):165-72.

144. Baselga J, Albanell J, Ruiz A, Lluch A, Gascon P, Guillem V, et al. Phase II and tumor pharmacodynamic study of gefitinib in patients with advanced breast cancer. J Clin Oncol. 2005;23(23):5323-33.

145. Dickler MN, Cobleigh MA, Miller KD, Klein PM, Winer EP. Efficacy and safety of erlotinib in patients with locally advanced or metastatic breast cancer. Breast Cancer Res Treat. 2009;115(1):115-21.

146. Bernsdorf M, Ingvar C, Jorgensen L, Tuxen MK, Jakobsen EH, Saetersdal A, et al. Effect of adding gefitinib to neoadjuvant chemotherapy in estrogen receptor negative early breast cancer in a randomized phase II trial. Breast Cancer Res Treat. 2011;126(2):463-70.

147. Schuler M, Awada A, Harter P, Canon JL, Possinger K, Schmidt M, et al. A phase II trial to assess efficacy and safety of afatinib in extensively pretreated patients with HER2-negative metastatic breast cancer. Breast Cancer Res Treat. 2012;134(3):1149-59.

148. Carey LA, Rugo HS, Marcom PK, Mayer EL, Esteva FJ, Ma CX, et al. TBCRC 001 randomized phase II study of cetuximab in combination with carboplatin in stage IV triple-negative breast cancer. J Clin Oncol. 2012;30(21):2615-23.

149. Baselga J, Gomez P, Greil R, Braga S, Climent MA, Wardley AM, et al. Randomized phase II study of the anti-epidermal growth factor receptor monoclonal antibody cetuximab with cisplatin versus cisplatin alone in patients with metastatic triple-negative breast cancer. J Clin Oncol. 2013; 31(20):2586-92.

150. Tredan O, Campone M, Jassem J, Vyzula R, Coudert B, Pacilio C, et al. Ixabepilone alone or with cetuximab as first-line treatment for advanced/ metastatic triple-negative breast cancer. Clin Breast Cancer. 2015;15(1):8-15.

151. Crozier JA, Advani PP, LaPlant B, Hobday T, Jaslowski AJ, Moreno-Aspitia A, et al. N0436 (Alliance): A Phase II Trial of Irinotecan With Cetuximab in Patients With Metastatic Breast Cancer Previously Exposed to Anthra-cycline and/or Taxane-Containing Therapy. Clin Breast Cancer. 2016;16(1):23-30.

152. Nabholtz JM, Abrial C, Mouret-Reynier MA, Dauplat MM, Weber B, Gligorov J, et al. Multicentric neoadjuvant phase II study of panitumumab combined with an anthracycline/taxane-based chemotherapy in operable triplenegative breast cancer: identification of biologically defined signatures predicting treatment impact. Ann Oncol. 2014;25(8):1570-7.

153. Nabholtz JM, Chalabi N, Radosevic-Robin N, Dauplat MM, Mouret-Reynier MA, Van Praagh I, et al. Multicentric neoadjuvant pilot Phase II study of cetuximab combined with docetaxel in operable triple negative breast cancer. Int J Cancer. 2016;138(9):2274-80.

154. Cowherd S, Miller LD, Melin SA, Akman S, Isom S, Cole J, et al. A phase it clinical trial of weekly paclitaxel and carboplatin in combination with panitumumab in metastatic triple negative breast cancer. Cancer Biol Ther. 2015;16(5):678-83.

155. Layman RM, Ruppert AS, Lynn M, Mrozek E, Ramaswamy B, Lustberg $M B$, et al. Severe and prolonged lymphopenia observed in patients treated with bendamustine and erlotinib for metastatic triple negative breast cancer. Cancer Chemother Pharmacol. 2013;71(5):1183-90.

156. Miles D, Cameron D, Bondarenko I, Manzyuk L, Alcedo JC, Lopez Rl, et al. Bevacizumab plus paclitaxel versus placebo plus paclitaxel as first-line therapy for HER2-negative metastatic breast cancer (MERiDiAN): A doubleblind placebo-controlled randomised phase III trial with prospective biomarker evaluation. Eur J Cancer. 2017:70:146-55.

157. Gligorov J, Doval D, Bines J, Alba E, Cortes P, Pierga J-Y, et al. Maintenance capecitabine and bevacizumab versus bevacizumab alone after initial firstline bevacizumab and docetaxel for patients with HER2-negative metastatic 
breast cancer (IMELDA): a randomised, open-label, phase 3 trial. Lancet Oncol. 2014;15(12):1351-60.

158. Bergh J, Bondarenko IM, Lichinitser MR, Liljegren A, Greil R, Voytko NL, et al. First-line treatment of advanced breast cancer with sunitinib in combination with docetaxel versus docetaxel alone: results of a prospective, randomized phase III study. J Clin Oncol. 2012;30(9):921-9.

159. De P, Hasmann M, Leyland-Jones B. Molecular determinants of trastuzumab efficacy: what is their clinical relevance? Cancer Treat Rev. 2013;39(8):925-34

160. Roberti MP, Rocca YS, Amat M, Pampena MB, Loza J, Coló F, et al. IL-2-or IL15-activated NK cells enhance Cetuximab-mediated activity against triplenegative breast cancer in xenografts and in breast cancer patients. Breast Cancer Res Treat. 2012;136(3):659-71.

161. El Guerrab A, Bamdad M, Bignon YJ, Penault-Llorca F, Aubel C. Anti-EGFR monoclonal antibodies enhance sensitivity to DNA-damaging agents in BRCA1-mutated and PTEN-wild-type triple-negative breast cancer cells. Mol Carcinog. 2017;56(5):1383-94.

162. Mazorra Z, Lavastida A, Concha-Benavente F, Valdés A, Srivastava RM, García-Bates TM, et al. Nimotuzumab induces NK cell activation, cytotoxicity, dendritic cell maturation and expansion of EGFR-specific T cells in head and neck cancer patients. Front Pharmacol. 2017;8:382.

163. Dienstmann R, Tabernero J. Necitumumab, a fully human lgG1 mAb directed against the EGFR for the potential treatment of cancer. Curr Opin Investig Drugs. 2010;11(12):1434-41.

164. Zhang X, Zhang B, Liu J, Liu J, Li C, Dong W, et al. Mechanisms of gefitinibmediated reversal of tamoxifen resistance in MCF-7 breast cancer cells by inducing ERa re-expression. Sci Rep. 2015;5:7835.

165. Yamasaki F, Zhang D, Bartholomeusz C, Sudo T, Hortobagyi GN, Kurisu K, et al. Sensitivity of breast cancer cells to erlotinib depends on cyclindependent kinase 2 activity. Mol Cancer Ther. 2007;6(8):2168-77.

166. Hurvitz SA, Shatsky R, Harbeck N. Afatinib in the treatment of breast cancer. Expert Opin Investig Drugs. 2014;23(7):1039-47.

167. Liu CY, Huang TT, Huang CT, Yang HP, Tseng LM, Shiau CW, et al. Pan-HER inhibitor, varlitinib, disrupts HER/ERK signaling and causes apoptosis in triple-negative breast. Cancer Cells. 2017; https://doi.org/10.1158/1538-7445. AM2017-2087.

168. Kalous O, Conklin D, Desai AJ, O'Brien NA, Ginther C, Anderson L, et al. Dacomitinib (PF-00299804), an irreversible Pan-HER inhibitor, inhibits proliferation of HER2-amplified breast cancer cell lines resistant to trastuzumab and lapatinib. Mol CancerTher. 2012;11(9):1978-87.

169. Morrison G, Fu X, Shea M, Nanda S, Giuliano M, Wang T, et al. Therapeutic potential of the dual EGFR/HER2 inhibitor AZD8931 in circumventing endocrine resistance. Breast Cancer Res Treat. 2014; 144(2):263-72

170. Morabito A, Piccirillo MC, Falasconi F, De Feo G, Del Giudice A, Bryce J, et al. Vandetanib (ZD6474), a dual inhibitor of vascular endothelial growth factor receptor (VEGFR) and epidermal growth factor receptor (EGFR) tyrosine kinases: current status and future directions. Oncologist. 2009;14(4):378-90

171. Echavarria I, López-Tarruella S, Márquez-Rodas I, Jerez Y, Martin M. Neratinib for the treatment of HER2-positive early stage breast cancer. Expert Rev Anticancer Ther. 2017;7(8):669-79.

172. Wong TW, Lee FY, Emanuel S, Fairchild C, Fargnoli J, Fink B, et al. Antitumor and antiangiogenic activities of BMS-690514, an inhibitor of human EGF and VEGF receptor kinase families. Clin Cancer Res. 2011;17(12):4031-41.

173. Traxler P, Allegrini PR, Brandt R, Brueggen J, Cozens R, Fabbro D, et al. AEE788: a dual family epidermal growth factor receptor/ErbB2 and vascular endothelial growth factor receptor tyrosine kinase inhibitor with antitumor and antiangiogenic activity. Cancer Res. 2004;64(14):4931-41.

174. Nguyen M, Lin KK, Burbridge MF, Simmons AD, Harding TC. Abstract 784: Nonclinical activity of the FGFR, VEGFR and PDGFR inhibitor lucitanib in FGFR3 translocated tumor models. Cancer Res. 2015; https://doi.org/10. 1158/1538-7445.AM2015-784.

175. Ferrara N, Hillan K, Gerber HP, Novotny W. Discovery and development of bevacizumab, an anti-VEGF antibody for treating cancer. Nat Rev Drug Discov. 2004;3(5):391-400.

176. Ferrer-Soler L, Vazquez-Martin A, Brunet J, Menendez JA, De Llorens R, Colomer R. An update of the mechanisms of resistance to EGFR-tyrosine kinase inhibitors in breast cancer: Gefitinib (Iressa $a^{T M}$ )-induced changes in the expression and nucleo-cytoplasmic trafficking of HER-ligands. Int J Mol Med. 2007;20(1):3-10.
177. Chell V, Balmanno K, Little AS, Wilson M, Andrews S, Blockley L, et al. Tumour cell responses to new fibroblast growth factor receptor tyrosine kinase inhibitors and identification of a gatekeeper mutation in FGFR3 as a mechanism of acquired resistance. Oncogene. 2013;32(25):3059-70.

178. Luo M, Fu LW. Redundant kinase activation and resistance of EGFR-tyrosine kinase inhibitors. Am J Cancer Res. 2014;4(6):608-24.

179. Rexer BN, Arteaga CL. Intrinsic and acquired resistance to HER2-targeted therapies in HER2 gene-amplified breast cancer: mechanisms and clinical implications. Crit Rev Oncog. 2012;17(1):1-16.

180. Shattuck DL, Miller JK, Carraway KL, Sweeney C. Met receptor contributes to trastuzumab resistance of Her2-overexpressing breast cancer cells. Cancer Res. 2008;68(5):1471-7.

181. Mueller KL, Hunter LA, Ethier SP, Boerner JL. Met and c-Src cooperate to compensate for loss of epidermal growth factor receptor kinase activity in breast cancer cells. Cancer Res. 2008:68(9):3314-22.

182. Tomlinson DC, Knowles MA, Speirs V. Mechanisms of FGFR3 actions in endocrine resistant breast cancer. Int J Cancer. 2012;130(12):2857-66.

183. Mukohara T. PI3K mutations in breast cancer: prognostic and therapeutic implications. Breast Cancer (Dove Med Press). 2015;7:111-23.

184. Bottsford-Miller JN, Coleman RL, Sood AK. Resistance and escape from antiangiogenesis therapy: clinical implications and future strategies. J Clin Oncol. 2012:30(32):4026-34.

185. Shojaei F, Ferrara N. Refractoriness to antivascular endothelial growth factor treatment: role of myeloid cells. Cancer Res. 2008;68(14):5501-4.

186. Ghatak S, Misra S, Toole BP. Hyaluronan oligosaccharides inhibit anchorageindependent growth of tumor cells by suppressing the phosphoinositide 3-kinase/Akt cell survival pathway. J Biol Chem. 2002;277(41):38013-20.

187. Pályi-Krekk Z, Barok M, Isola J, Tammi M, Szöllo J, Nagy P. Hyaluronaninduced masking of ErbB2 and CD44-enhanced trastuzumab internalisation in trastuzumab resistant breast cancer. Eur J Cancer. 2007;43(16):2423-33.

188. Chandarlapaty S, Scaltriti M, Angelini P, Ye Q, Guzman M, Hudis CA, et al. Inhibitors of HSP90 block p95-HER2 signaling in Trastuzumab-resistant tumors and suppress their growth. Oncogene. 2010;29(3):325-34.

189. Ozkavruk Eliyatkin N, Aktas S, Ozgur H, Ercetin P, Kupelioglu A. The role of p95HER2 in trastuzumab resistance in breast cancer. J BUON. 2016;21 (2):382-9.

190. Rexer BN, Ghosh R, Narasanna A, Estrada MV, Chakrabarty A, Song Y, et al. Human breast cancer cells harboring a gatekeeper T798M mutation in HER2 overexpress EGFR ligands and are sensitive to dual inhibition of EGFR and HER2. Clin Cancer Res. 2013;19(19):5390-401.

191. Hanker AB, Brewer MR, Sheehan JH, Koch JP, Sliwoski GR, Nagy R, et al. An acquired HER2 T798l gatekeeper mutation induces resistance to Neratinib in a patient with HER2 mutant-driven breast cancer. Cancer Discov. 2017;7(6): $575-85$.

\section{Submit your next manuscript to BioMed Central and we will help you at every step:}

- We accept pre-submission inquiries

- Our selector tool helps you to find the most relevant journal

- We provide round the clock customer support

- Convenient online submission

- Thorough peer review

- Inclusion in PubMed and all major indexing services

- Maximum visibility for your research

Submit your manuscript at www.biomedcentral.com/submit
Biomed Central 